Article

\title{
Comparison of Pressure-Retarded Osmosis Performance between Pilot-Scale Cellulose Triacetate Hollow-Fiber and Polyamide Spiral-Wound Membrane Modules
}

\author{
Yuriko Kakihana ${ }^{1,2}$, Nora Jullok ${ }^{3,4}\left(\mathbb{D}\right.$, Masafumi Shibuya $^{1}$, Yuki Ikebe ${ }^{1}$ and Mitsuru Higa ${ }^{1,2, *(1)}$ \\ 1 Graduate School of Sciences and Technology for Innovation, Yamaguchi University, 1677-1 Yoshida, \\ Yamaguchi 753-8511, Japan; kakihana@yamaguchi-u.ac.jp (Y.K.); glory.color413@gmail.com (M.S.); \\ a066vfu@yamaguchi-u.ac.jp (Y.I.) \\ 2 Blue Energy Center for SGE Technology (BEST), 2-16-1 Tokiwadai, Ube, Yamaguchi 755-8611, Japan \\ 3 Faculty of Chemical Engineering Technology, Universiti Malaysia Perlis, Kompleks Pusat Pengajian Jejawi 3, \\ Jejawi 02600, Perlis, Malaysia; norajullok@unimap.edu.my \\ 4 Centre of Excellence for Biomass Utilization, Universiti Malaysia Perlis, Pusat Pengajian Jejawi 3, \\ Jejawi 02600, Perlis, Malaysia \\ * Correspondence: mhiga@yamaguchi-u.ac.jp; Tel.: +81-836-85-9203
}

check for updates

Citation: Kakihana, Y.; Jullok, N.; Shibuya, M.; Ikebe, Y.; Higa, M. Comparison of Pressure-Retarded Osmosis Performance between Pilot-Scale Cellulose Triacetate Hollow-Fiber and Polyamide Spiral-Wound Membrane Modules. Membranes 2021, 11, 177. https:// doi.org/10.3390/membranes11030177

Academic Editor: Oumarou Savadogo

Received: 1 February 2021

Accepted: 25 February 2021

Published: 28 February 2021

Publisher's Note: MDPI stays neutral with regard to jurisdictional claims in published maps and institutional affiliations.

Copyright: (c) 2021 by the authors. Licensee MDPI, Basel, Switzerland. This article is an open access article distributed under the terms and conditions of the Creative Commons Attribution (CC BY) license (https:// creativecommons.org/licenses/by/ $4.0 /)$.

\begin{abstract}
Pressure-retarded osmosis (PRO) has recently received attention because of its ability to generate power via an osmotic pressure gradient between two solutions with different salinities: high- and low-salinity water sources. In this study, PRO performance, using the two pilot-scale PRO membrane modules with different configurations-five-inch cellulose triacetate hollow-fiber membrane module (CTA-HF) and eight-inch polyamide spiral-wound membrane modules (PASW) — was evaluated by changing the draw solution (DS) concentration, applied hydrostatic pressure difference, and the flow rates of DS and feed solution (FS), to obtain the optimum operating conditions in PRO configuration. The maximum power density per unit membrane area of PA-SW at $0.6 \mathrm{M}$ $\mathrm{NaCl}$ was $1.40 \mathrm{~W} / \mathrm{m}^{2}$ and 2.03-fold higher than that of CTA-HF, due to the higher water permeability coefficient of PA-SW. In contrast, the maximum power density per unit volume of CTA-SW at $0.6 \mathrm{M}$ $\mathrm{NaCl}$ was $4.67 \mathrm{~kW} / \mathrm{m}^{3}$ and 6.87-fold higher than that of PA-SW. The value of CTA-HF increased to $13.61 \mathrm{~kW} / \mathrm{m}^{3}$ at $1.2 \mathrm{M} \mathrm{NaCl}$ and was 12.0 -fold higher than that of PA-SW because of the higher packing density of CTA-HF.
\end{abstract}

Keywords: pressure-retarded osmosis; pilot scale; hollow fiber; spiral wound; power density

\section{Introduction}

Energy demand is increasing globally, in tandem with economic development and population growth. Because the majority of primary energy sources comes from fossil fuels [1], the world is facing crucial challenges in meeting energy-source demands, owing to the decrease in the accessibility of cheap fossil fuels [2]. Moreover, damaging greenhouse gas emissions ultimately contribute to climate change [3]. Many research efforts have focused on developing efficient alternative energy sources: Solar, wind, tidal, wave, and biomass have been extensively studied as alternative and sustainable energy sources. However, the varying availability of energy sources, complex logistics, and high installation costs still prevent their widespread implementation.

Furthermore, water shortages are among society's most challenging problems, for which seawater reverse-osmosis desalination (SWRO) is a promising solution. Although the concentrated brine coming from desalination plants sometimes causes environmental problems [4], owing to its high salinity, it can be used as a valuable energy resource referred to as salinity gradient energy (SGE) [5-8]. SGE is a renewable energy source that is obtained by mixing two salt solutions with different salinities $[9,10]$. There are two main membranebased technologies that convert SGE into electricity: reverse electrodialysis (RED) $[9,11,12]$ 
and pressure-retarded osmosis (PRO) [10,13]. RED generates energy by converting counterion permselective transport with ion-exchange membranes to electric current by redox reactions at two electrodes; there have been reports on large-scale RED systems [14-17]. In contrast, in a PRO system, a semi-permeable membrane (SPM) separates a low-salinity solution, the feed solution (FS), from a pressurized high-salinity solution, called the draw solution (DS).

The advantages of using SWRO brine as the DS of PRO or RED are as follows: The high salinity of the brine provides high power output for RED and PRO systems and the intake, and the pretreatment of DS supplied to the two systems is associated with a lower cost, as well as increased energy savings.

Both the technologies have associated advantages, as well as disadvantages: The gross power density of PRO is higher than that of RED; however, especially in small-scale plants, the low energy conversion efficiency of the high-pressure pumps, pressure exchanger, turbine, and generator of PRO results in a lower net power than in the RED. The effect of the bivalent ions in the seawater and the SWRO brine increases the power output of PRO, while decreasing the output of RED. Currently, the cost of membranes for RED is higher than that for PRO [18].

There was an attempt to compare both PRO and RED, using experimental data obtained from the literature; however, it was unsuccessful, owing to incomplete sets of equal performance data. In 2007, Post et al. [5] developed a model in which each equation was compared to its equivalent for PRO and RED. Based on the developed model, both with respect to power density and energy recovery, it was concluded that each technique has its own field of application; PRO is more suitable for power generation using concentrated saline brines, whereas RED is more effective for power generation using seawater and river water. Details of the comparison between PRO and RED based on the developed model can be found in the literature [5].

In PRO, the osmotic water flow occurs from the FS to the DS through the membrane and propels a turbine connected to a generator to generate electricity. Figure 1 shows the water flux and water molecule movement in a dialysis system consisting of SPM, FS, and DS, which explains the principle of forward osmosis (FO), PRO, and reverse osmosis (RO). Here, SPM is assumed to have ideal water permeability. First, there is no hydrostatic pressure difference between the FS and DS sides. In this case, the movement of water molecules from FS to DS (WM1), shown by the dotted line in Figure 1, is higher than that from DS to FS (WM2), shown by a broken line, because the thermal mobility of water molecules near the membrane surface at the FS side is higher than that at the DS side because of the presence of non-permeable ions in DS. Therefore, the net water flux defined by subtracting WM1 from WM2 shows a negative value, as shown by the solid line in Figure 1. This phenomenon is called forward osmosis. When the hydrostatic pressure difference $(\Delta P)$ is applied to the DS side, WM2 increases with increasing $\Delta P$, while WM1 is independent of the pressure. Hence, the net water flux increases with increasing $\triangle P$. At the point where WM1 is equal to WM2, the net water flux becomes zero. The $\Delta P$ at this point is called the osmotic pressure difference $(\Delta \pi)$ between the DS and FS. In the case where $\Delta P$ is larger than $\Delta \pi$, the net water flux becomes a positive value, which is called the reverse osmosis mode. PRO is operated at applied hydrostatic pressures $0<\Delta P<\Delta \pi$ so that the volume of pressurized DS increases by the net water flux to rotate a turbine to generate energy [19]. 


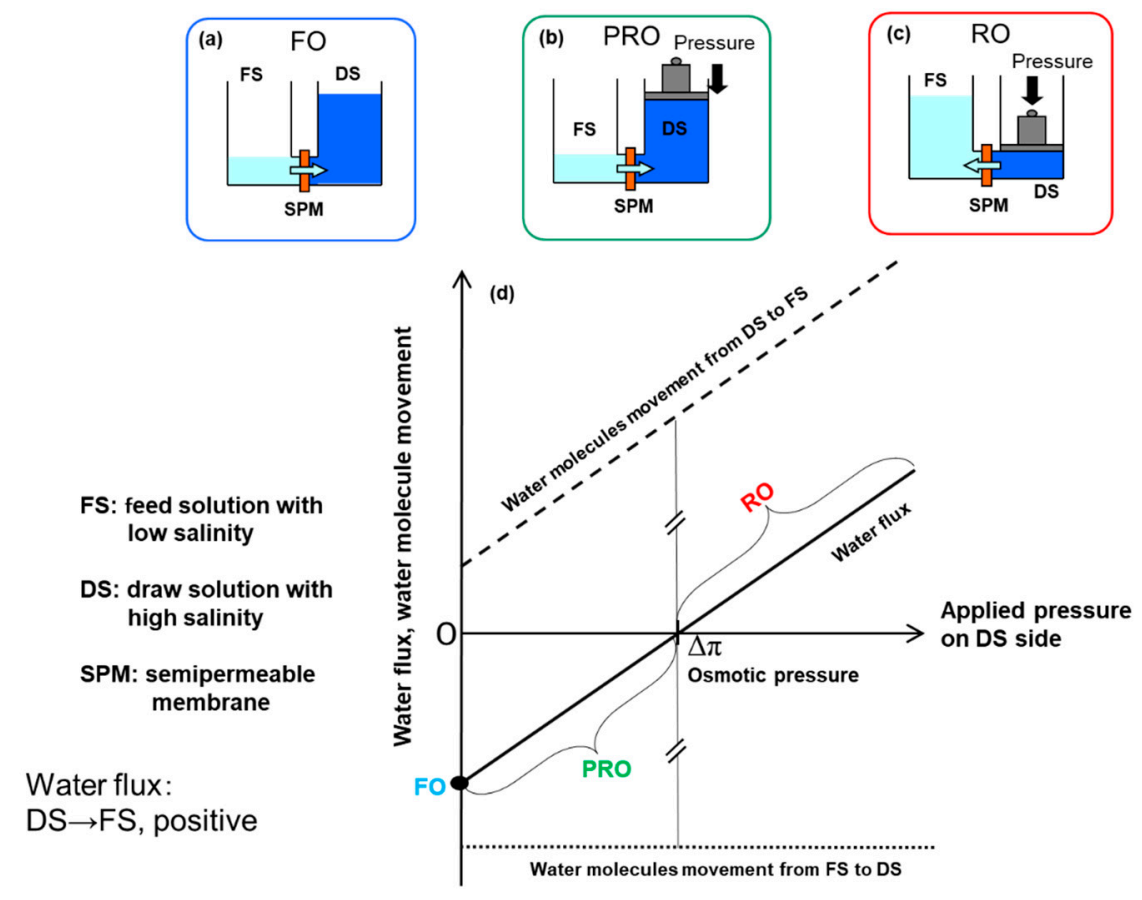

Figure 1. Water flux and water molecule movement in a dialysis system consisting of semi-permeable membrane (SPM), feed solution (FS), and draw solution (DS), to explain principle of forward osmosis (FO), pressure-retarded osmosis PRO, and reverse osmosis (RO).

Realizing the potential of $\mathrm{PRO}$, intensive studies have been conducted, using laboratoryscale PRO analysis, utilizing coupon-size membranes [20-26] and small hollow-fiber (HF) modules [27-33]. Several bench-scale investigations have demonstrated promising results and, to some extent, the membrane power density reaches $60 \mathrm{~W} / \mathrm{m}^{2}$ at a high pressure of 48 bar with a $3 \mathrm{M} \mathrm{NaCl}$ DS using a thin-film composite membrane [34]. However, with regard to upscaling, the performance of the scaled-up prototype may differ significantly from the laboratory data. This is because the real plant scale of the PRO system, for instance, depends not only on the membrane parameters but also on the membrane orientation/membrane configuration, and the operational conditions such as the flow rates of the DS and FS and the operating pressure [10,35]. The need for the evaluation of power generation utilizing PRO at the near industrial scale is therefore vital to determine its real potential and to narrow down the gap between theoretical and practical applications. To understand the effect of the abovementioned factors on PRO performance, evaluations using spiral-wound (SW) modules [36,37] and HF modules were investigated. Saito et al. [4] performed PRO tests of a 10-inch HF module using high-concentration brine from a seawater $\mathrm{RO}$ plant and sewage-treated water from a regional sewage-treated center as DS and FS, respectively, and obtained $7.7 \mathrm{~W} / \mathrm{m}^{2}$ of a maximum gross power density at 2.5 MPa of hydraulic pressure difference. Sakai et al. [38] obtained $13.5 \mathrm{~W} / \mathrm{m}^{2}$ of power density, using a 10-inch HF PRO module. Experiments and simulation studies of PRO performance, using pilot-scale PRO HF modules under various operational conditions, have also been performed [35,39-46]. In previous studies [35,43], the module performance with volumetric-based power outputs, as well as membrane-area-based power density, was investigated, to compare the PRO performance between the two different module configurations. However, to the best of the authors' knowledge, there have been no studies on systematic PRO performance evaluation of pilot-scale SW and HF membrane modules based on experimental data under the same operating conditions, to compare the PRO performance between SW and HF configurations. In this study, the performance of two types of pilot-scale membrane modules with $\mathrm{HF}$ and SW configurations is investigated under a wide range of PRO operating conditions: DS concentrations, the flow rates of DS and FS, and applied hydraulic pressure differences; furthermore, the PRO performance 
between the two modules is compared to provide useful insights into the design of largescale PRO plants.

\section{Experimental}

\subsection{Materials and Chemicals}

Tap water was first treated with activated carbon to remove any traces of chlorine prior to use as the FS and for the preparation of DS. DS was prepared by using analytical-grade sodium chloride ( $\mathrm{NaCl}$, Nacalai Tesque Co., Ltd., Kyoto, Japan) dissolved in chlorine-free tap water.

\subsection{Cellulose Triacetate Hollow-Fiber (CTA-HF) and Polyamide Spiral-Wound (PA-SW) Membrane Modules}

An open-ended HF type of cellulose triacetate (CTA) designed for PRO applications from Toyobo Co. Ltd (CTA-HF) and a prototype polyamide thin film composite membrane module (PA-SW) were used. The membrane modules have four open ports: an inlet and an outlet for DS and FS. The specifications of CTA-HF and PA-SW are listed in Table 1.

Table 1. Specifications of the cellulose triacetate hollow-fiber (CTA-HF) and polyamide spiral-wound (PA-SW) membrane modules used in this study.

\begin{tabular}{ccc}
\hline & CTA-HF & PA-SW \\
\hline Active layer of membrane & Cellulose triacetate & polyamide \\
Number of ports & 4 & 4 \\
Module diameter $(\mathrm{mm})$ & 136 & 203.2 \\
Module length $(\mathrm{mm})$ & 683 & 1016 \\
Inner diameter of hollow fiber, $\mathrm{d}_{\text {in }}(\mu \mathrm{m})$ & 90 & - \\
Outer diameter of hollow fiber, $\mathrm{d}_{\text {out }}(\mu \mathrm{m})$ & 170 & - \\
Number of hollow fibers & 187,000 & 15.3 \\
Membrane area, $\left(\mathrm{m}^{2}\right)$ & 67 & $3.3 \times 10^{-2}$ \\
Module volume, $\left(\mathrm{m}^{3}\right)$ & $9.92 \times 10^{-3}$ & 464 \\
Packing density $\left(\mathrm{m}^{2} / \mathrm{m}^{3}\right)$ & 6754 &
\end{tabular}

\subsection{RO Experiment}

A preliminary analysis in reverse osmosis $(\mathrm{RO})$ mode was conducted to determine the water permeability $(A)$ and salt permeability $(B)$ of the membrane used in the two CTA-HF and PA-SW modules. Figure 2 presents a schematic of the evaluation system of a pilot-scale PRO module. The system was the same as in a previous study [35], and was also used for the RO evaluation test in this study. The concentration of FS in the test was 500 ppm $\mathrm{NaCl}$. To operate the system in $\mathrm{RO}$ mode, valve V2 was completely closed, so that the permeated water flowed out from the outlet at the FS side of the module. The activated carbon-treated tap water was fed into the DS side of the membrane module with an inlet flow rate of $4.0 \mathrm{~L} / \mathrm{min}$. The applied pressure difference between the DS and FS was carefully controlled, using valve V3. The water permeation flux was measured, using a flow meter at the FS outlet. The $A\left(\mathrm{~m} \mathrm{~s}^{-1} \mathrm{~Pa}^{-1}\right)$ value was then determined from the slope of the graph plotted for water flux over the applied pressure according to Equation (1):

$$
J_{w}=A(\Delta P-\Delta \pi)
$$

where $J_{w}$ is the water flux $\left(\mathrm{L} \mathrm{m}^{-2} \mathrm{~h}^{-1}\right), \Delta P$ is the hydraulic pressure difference, and $\Delta \pi$ is the osmotic pressure difference. To determine the value of $B$, Equation (2) was applied [25]:

$$
B=\frac{A(\Delta P-\Delta \pi)(1-R)}{R}
$$


where the rejection rate, $R$, is calculated, using Equation (3).

$$
R=1-\frac{C_{p}}{C_{F}}
$$

where $C_{p}$ is the concentration at the permeate side, and $C_{F}$ is the concentration at the feed solution.

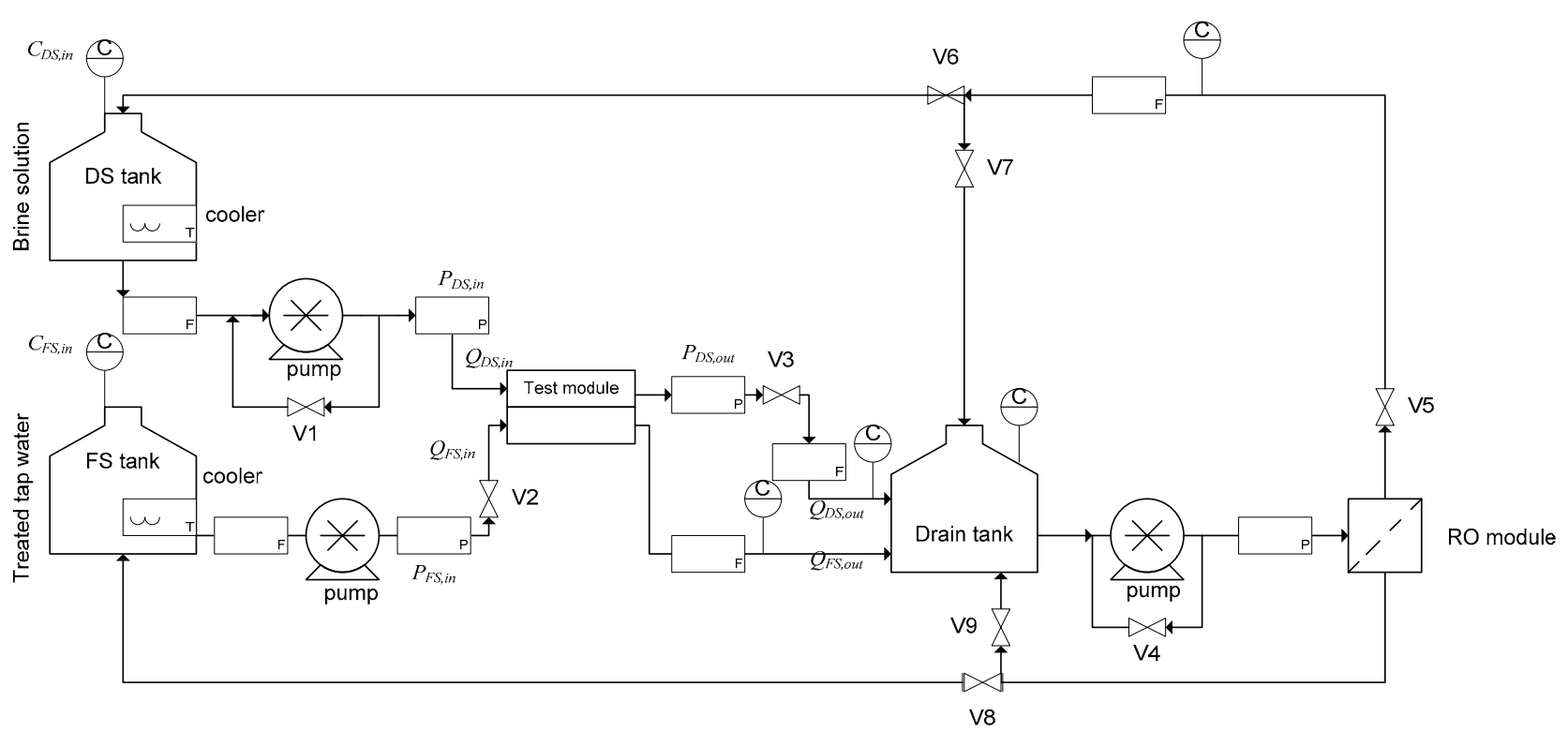

Figure 2. Schematic of the pilot-scale PRO evaluation system used in this study. C represents conductivity meter, $\mathrm{F}$ is flow meter, $\mathrm{V}$ is valve, and $\mathrm{P}$ is the pressure gauge.

\subsection{PRO Experiment}

To evaluate the performance in PRO mode, a PRO test was performed, using the system shown in Figure 2. Tap water was fed to the system as FS, using a low-pressure pump, and $\mathrm{NaCl}$ solutions of various concentrations were fed as DS. The inlet concentrations of FS and DS were measured, using a conductivity meter; the flow rates of the inlet and outlet at the DS and FS sides were measured, using flow meters; and the pressure at each position $\left(P_{\mathrm{FS}, \text { in }}, P_{\mathrm{DS}, \text { in }}\right.$ and $\left.P_{\mathrm{DS}, \text { out }}\right)$ was measured, using a pressure gauge. The inlet flow rate of the FS was set between 2.0 and $6.0 \mathrm{~L} / \mathrm{min}$, while the DS inlet flow rate was between 2.0 and $10.0 \mathrm{~L} / \mathrm{min}$. The maximum flow rates of FS and DS at the tests were 6.0 and $10 \mathrm{~L} / \mathrm{min}$, respectively, owing to the pump limitation created by the evaluation system.

During PRO evaluation, DS was diluted by the permeated water from the FS, and the salt concentration in the FS was increased by the reverse salt flux from the DS (DS leakage). A regeneration system with $\mathrm{RO}$ was added after the PRO unit to obtain steady-state conditions during the PRO test. To regenerate both the DS and FS, the needle valves V4 and $\mathrm{V} 5$ were used to control the concentration of the brine and permeate at their respective initial FS and DS concentrations. Thus, a steady-state long-standing module operation was achieved, using a hybrid PRO and RO regeneration unit. Each data point was logged and recorded on a computer $5 \mathrm{~min}$ after the parameter was adjusted at $10 \mathrm{~s}$ intervals. The PRO performances of the CTA-HF and PA-SW membrane modules were evaluated under various operating parameters. The permeate water flow rate $\left(Q_{w}\right)$ through the module was determined, using the inlet and outlet flow rates of FS, $Q_{\mathrm{FS} \text {, in }}$ and $Q_{\mathrm{FS}, \text { out, }}$ respectively, using Equation (4):

$$
Q_{w}=Q_{\mathrm{FS}, \text { in }}-Q_{\mathrm{FS}, \text { out }}
$$


The permeate flux $\left(J_{w}\right)$ through the membrane module was determined, using Equation (5), and is the division of the permeate water flow rate by the membrane area $\left(S_{m}\right)$.

$$
J_{w}=\frac{Q_{w}}{S_{m}}
$$

The permeation rate $(\eta)$ of the FS side was determined by using Equation (6):

$$
\eta \equiv \frac{Q_{w}}{Q_{\mathrm{FS}, \text { in }}} \times 100 \%
$$

When $\eta=100$, all solutions on the FS side permeated to the DS side. The dilution factor $(\varphi)$ on the DS side was defined, using the inlet flow rate of the DS $\left(Q_{\mathrm{DS}, \text { in }}\right)$ and $Q_{w}$, as in Equation (7):

$$
\varphi \equiv 1+\frac{Q_{w}}{Q_{\mathrm{DS}, \mathrm{in}}}
$$

When $Q_{\mathrm{DS}, \text { in }}{ }^{\prime} Q_{w}, \varphi$ is close to unity. This implies that the DS outlet concentration was nearly equal to the DS inlet concentration, indicating that the DS dilution effect was negligible.

To estimate the reverse salt flux $\left(J_{S}\right)$, Equation (8) was employed:

$$
J_{s}=\frac{\left(Q_{\mathrm{FS}, \text { out }} \times C_{\mathrm{FS}, \mathrm{out}}-Q_{\mathrm{FS}, \text { in }} \times C_{\mathrm{FS}, \text { in }}\right)}{S_{m}}
$$

Many PRO evaluations in the literature [10,12,13,19-34] are based on the power density per membrane area to characterize the membrane performance. The membrane area-based power density $\left(P D^{\text {area }}\right)$ is defined as the effective membrane area-based power density and is calculated by using Equation (9):

$$
P D^{\text {area }}=J_{w} \Delta P
$$

From an industrial point of view, module volume-based PRO performance is vital because the volume-based size and number of required modules are necessary for designing a full-scale PRO plant $[35,43,45]$. The module volume-based gross power density $\left(P D^{\text {vol }}\right)$ used in this study is expressed as follows:

$$
P D^{\mathrm{vol}}=J_{w}^{\mathrm{vol}} \Delta P
$$

$J_{w}^{\mathrm{vol}}$ is module volume-based water flux expressed as

$$
J_{w}^{\mathrm{vol}}=\frac{Q_{w}}{V_{\mathrm{mod}}}
$$

where $V_{\text {mod }}$ is the module volume. From (9) and (10), $P D^{\text {vol }}$ is expressed, using $P D^{\text {area }}$ as follows:

$$
P D^{\text {vol }}=\beta P D^{\text {area }}
$$

where $\beta$ is the packing density of the membrane module and is defined by using the following equation:

$$
\beta=S_{m} / V_{\bmod }
$$

The power extracted from the PRO, using SGE, was determined by calculating the conversion efficiency to electrical energy. Electrical energy can significantly contribute to the establishment of the optimum operating conditions. To obtain the optimum operating conditions, the generated net power output $\left(W_{\text {net }}\right)$ must first be determined, using Equation (14) [38]:

$$
W_{\text {net }}=W_{\text {gross }}-\left(C E_{\mathrm{DS}}+C D_{\mathrm{FS}}\right)
$$




$$
\begin{gathered}
W_{\text {gross }}=P_{\mathrm{DS}, \text { out }} Q_{w} E_{\mathrm{G}} \\
P E_{\mathrm{DS}}=\frac{\left(P_{\mathrm{DS}, \text { in }}-P_{\mathrm{DS}, \text { out }} E_{\mathrm{px}}\right) Q_{\mathrm{DS}, \text { in }}}{E_{\mathrm{p}, \mathrm{DS}}} \\
P E_{\mathrm{FS}}=\frac{P_{\mathrm{FS}, \text { in }} Q_{\mathrm{FS}, \text { in }}}{E_{\mathrm{p}, \mathrm{FS}}}
\end{gathered}
$$

where $P E_{\mathrm{DS}}$ and $P E_{\mathrm{FS}}$ are the pumping energy at the $\mathrm{DS}$ and $\mathrm{FS}$ sides; $E_{\mathrm{p}, \mathrm{DS}}, E_{\mathrm{p}, \mathrm{FS}}, E_{\mathrm{G}}$, and $E_{\mathrm{px}}$ are the energy efficiencies of the DS pump, FS pump, electric generator, and pressure exchanger (PX), respectively. In this study, the values of $E_{\mathrm{G}}=0.9, E_{\mathrm{p}, \mathrm{DS}}=0.88, E_{\mathrm{p}, \mathrm{FS}}=0.88$, and $E_{\mathrm{px}}=0.92$ were assumed based on the values in the literature $[38,46]$.

\section{Results and Discussion}

\subsection{RO Tests for the Two Modules}

Figure 3a shows the water flux of PA-SW and CTA-HF plotted over the applied hydrostatic pressure $(\Delta P)$. The water flux increased with an increase in $\triangle P$. The water permeability ( $A$ value) was obtained from the slope of the solid line calculated by fitting the data to Equation (1) and gives $0.65 \times 10^{-12}$ and $4.6 \times 10^{-12}\left[\mathrm{~m} \mathrm{~s}^{-1} \mathrm{~Pa}^{-1}\right]$ for CTA-HF and PA-SW, respectively. The water permeability of PA-SW was approximately seven times higher than that of the hollow-fiber membrane module (CTA-HF). In general, the water permeability of a PA membrane is higher than that of a CTA membrane because the PA membrane has a thinner active layer than that of the CTA [4,42].

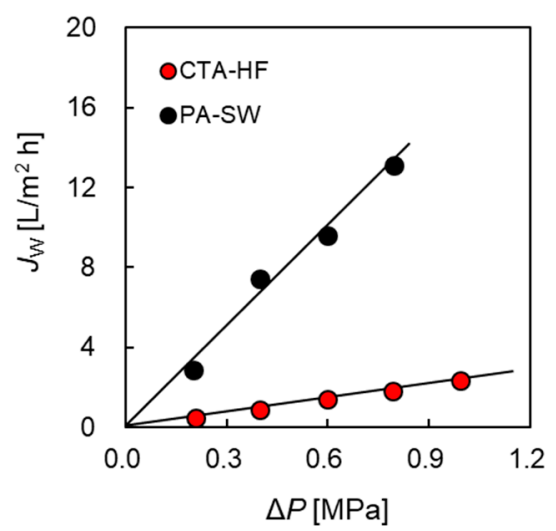

(a)

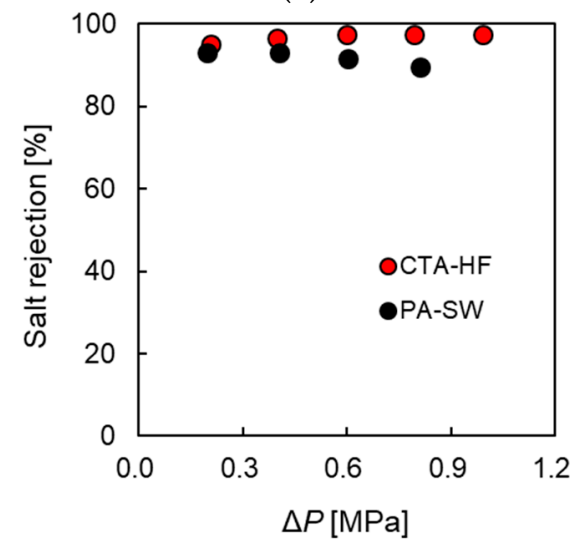

(b)

Figure 3. (a) Water flux and (b) salt rejection as a function of applied pressure in RO mode. QFs: $4.0 \mathrm{~L} / \mathrm{min}$. Tap water and $500 \mathrm{ppm} \mathrm{NaCl}$ were used as feed solution in the measurement of water flux and salt rejection, respectively. 
The salt rejection as a function of $\Delta P$, using $500 \mathrm{ppm} \mathrm{NaCl}$ aqueous as the FS, is shown in Figure 3b. It was found that the salt rejection of CTA-HF was higher than that of PA-SW. The salt permeability $(B)$ of CTA-HF and PA-SW was calculated by using Equation (2) from the salt rejection. The value of PA-SW was $2.23 \times 10^{-7}\left[\mathrm{~m} \mathrm{~s}^{-1}\right]$, approximately 13 times higher than that of CTA-HF $\left(0.17 \times 10^{-7}\left[\mathrm{~m} \mathrm{~s}^{-1}\right]\right)$. This indicates that the CTA-HF membrane will have a lower DS leakage than the PA-SW membrane.

\subsection{PRO Tests for the Two Modules}

\subsubsection{Effect of FS Inlet Flow Rates on PRO Modules Performance}

Generally, the performance of a PRO membrane module is lower than the theoretical value calculated in terms of Equation (9), owing to two factors: (a) external concentration polarization (ECP), which governs the water and solute permeation at the interface between the salt solution and the membrane surface, and (b) a decrease in between the DS and FS sides in the modules, owing to the water and salt permeation inside the module $[10,12,13,25,36,47]$. These phenomena decrease the PRO performance of the module and depend on the flow rates of the DS and FS. Hence, to obtain the optimum operating conditions for the two membrane modules, a systematic investigation of the effect of the inlet flow rate of DS and FS on PRO performance was conducted by measuring the water flux and the outlet concentration of DS and FS during the PRO tests, using 0.6 and $1.2 \mathrm{M}$ $\mathrm{NaCl}$ as the DS, and applying a predetermined hydrostatic pressure difference.

\section{Permeate Water Flux and Permeation Rate Versus FS Flow Rate}

To evaluate the effect of concentrative internal concentration polarization (ICP) inside the support layer, and the increase in salt concentration in FS due to DS leakage (FS upconcentration) on the PRO performance of the two modules, the evaluation of the effect of $Q_{\mathrm{FS}}$ on $J_{w}$, the permeation rate $(\eta)$, and the concentration of the module outlet at the FS side were investigated and are shown in Figure 4. Here, $0.6 \mathrm{M} \mathrm{NaCl}$ and tap water were used as DS and FS, respectively. The flow rate of DS (QDS) was set as $10.0 \mathrm{~L} / \mathrm{min}$ in all the evaluations, which was the maximum DS flow rate of the evaluation system. $\Delta P$ was set as 1.2 $\mathrm{MPa}$, which is almost half of the theoretical osmotic pressure difference between the DS and FS. Figure 4 a shows that $J_{w}$ of PA-SW gradually increased from 5.6 at $3.0 \mathrm{~L} / \mathrm{min}$ to $6.1 \mathrm{~L} / \mathrm{m}^{2} \mathrm{~h}$ at $6.0 \mathrm{~L} / \mathrm{min}$ with increasing $Q_{\mathrm{FS}}$, while that of CTA-HF from 1.4 at $2.0 \mathrm{~L} / \mathrm{min}$ to $1.6 \mathrm{~L} / \mathrm{m}^{2} \mathrm{~h}$ at $5.0 \mathrm{~L} / \mathrm{min}$. These results indicate that $J_{w}$ of the former module was more than 4 times higher than that of the latter, though the water permeability of the former was more than 13 times higher than that of the latter. The slight increase in $J_{w}$ of both modules with increasing $Q_{\mathrm{FS}}$ indicates that the effect of ICP on the PRO performance is almost negligible at high $Q_{\mathrm{FS}}$. Figure $4 \mathrm{~b}$ indicates that the permeate rate of the two modules decreased with increasing $Q_{\mathrm{FS}}$ and the value of CTA-HF decreased from $75 \%$ at $2.0 \mathrm{~L} / \mathrm{min}$ to less than $40 \%$ at $5 \mathrm{~L} / \mathrm{min}$, and that of PA-SW from $48 \%$ at $3.0 \mathrm{~L} / \mathrm{min}$ to $26 \%$ at $6 \mathrm{~L} / \mathrm{min}$. Figure $4 \mathrm{c}$ shows that FS outlet concentration $\left(Q_{\mathrm{FS}, \text { out }}\right)$ of both the modules was less than $0.05 \mathrm{M}$ and decreased with increasing $Q_{\mathrm{FS}}$. Increasing $Q_{\mathrm{FS}}$ helped to flush the salt in the FS that permeated from the DS side to the FS membrane interface. For a CTA-HF module, a permeation rate of less than $70 \%$ was required to mitigate the FS up-concentration [35]. $\mathrm{C}_{\mathrm{FS} \text {,out }}$ of the CTA-HF, was slightly lower than that of PA-SW, although the permeate rate of the former was slightly higher than that of the latter. This is because the $B$ value of the former is significantly lower than that of the latter. From the results shown in Figure $4 b, c$, an FS flow rate of more than $5 \mathrm{~L} / \mathrm{min}$ is sufficient for the two modules to mitigate the effect of FS up-concentration on the PRO performance. 


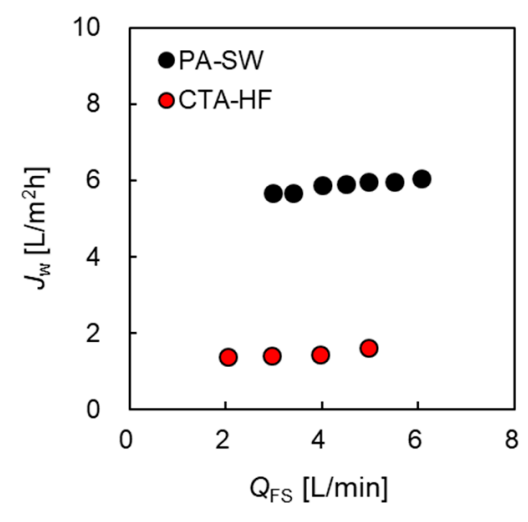

(a)

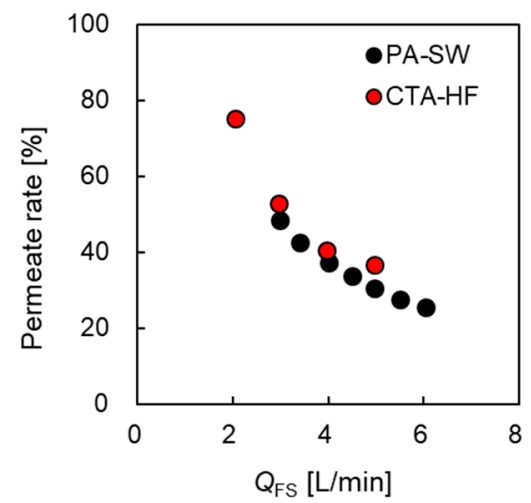

(b)

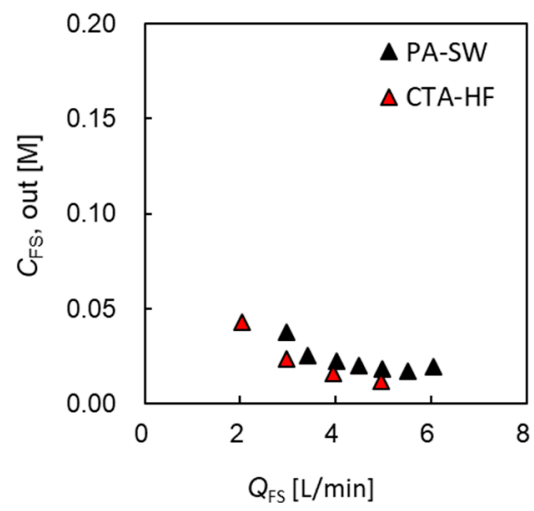

(c)

Figure 4. (a) Water flux, $J_{w}$, and (b) FS permeation rate, $\eta$, and (c) the concentration of the module outlet at FS side $\left(C_{\mathrm{FS} \text {,out }}\right)$, respectively, as a function of FS flow rate, $Q_{\mathrm{FS}}$. DS: $0.6 \mathrm{M} \mathrm{NaCl}$. FS: treated tap water. Flow rate of DS ( $\left.Q_{\mathrm{DS}}\right): 10.0 \mathrm{~L} / \mathrm{min}$. Hydrostatic pressure $(\Delta P): 1.2 \mathrm{MPa}$.

Figure 5 shows $J_{w}$ and $\eta$, and $Q_{\mathrm{FS} \text {,out }}$ as a function of $Q_{\mathrm{FS}}$ in the case of $1.2 \mathrm{M} \mathrm{NaCl}$ as DS. Here, $\Delta P$ for CTA-HF was $2.5 \mathrm{MPa}$, which is almost equal to $\Delta \pi$. There is no information about the pressure resistance for PA-SW. Hence, the PRO test using PA-SW was performed at a lower pressure than that using CTA-HF, i.e., 1.6 MPa.

In the case of 1.2 M DS, $J_{w}$ of CTA-HF at $6.0 \mathrm{~L} / \mathrm{min}$ of $Q_{\mathrm{FS}}$ was 1.56 times higher compared to that in the case of $0.6 \mathrm{M}$ though $\Delta P$ increased from 1.2 to $2.5 \mathrm{Mpa}$, because the increase in $\Delta \pi$ as the driving force of the water flux, as shown in Figure 5a. On the contrary, $J_{w}$ of PA-SW showed a low value of $85 \%$ of $J_{w}$ in the case of $0.6 \mathrm{M} \mathrm{NaCl}$. This is because the increase in the effective osmotic pressure difference in PA-SW did not increase linearly, as mentioned in Section 3.2.2. As shown in Figure 5b, the permeation rate in CTA-HF reached $100 \%$ at the lowest $Q_{\mathrm{FS}}(<2.5 \mathrm{~L} / \mathrm{min})$, and $C_{\mathrm{FS} \text {,out }}$ of the module had a high value of approximately $0.3 \mathrm{M}$, as shown in Figure 5c. Although the $J_{w}$ of CTA-HF is lower than that of PA-SW, the total membrane area of the former is more than four times larger than that of the latter; hence, the permeate water flow from the FS to the DS sides in the former module was larger than that in the latter. Therefore, an FS flow rate of $2.5 \mathrm{~L} / \mathrm{min}$ is not sufficient for CTA-HF to prevent FS up-concentration. $C_{\mathrm{FS} \text {,out }}$ decreased dramatically as $Q_{\mathrm{FS}}$ increased, and permeation rate decreased to less than $50 \%$ at $6.0 \mathrm{~L} / \mathrm{min}$ of $Q_{\mathrm{FS}}$, while that of PA-SW decreased from $40 \%$ to $20 \%$ at $6.0 \mathrm{~L} / \mathrm{min}$ of $Q_{\mathrm{FS}}$. Hence, these data indicate that 5.0 a $Q_{\mathrm{FS}}$ of is sufficient for both modules to mitigate FS up-concentration even at a high DS concentration of $1.2 \mathrm{M}$. 


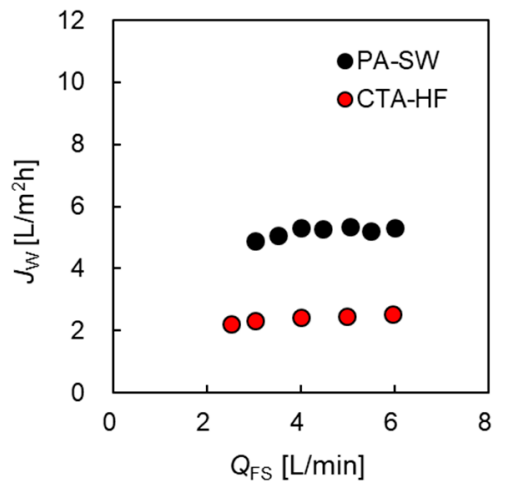

(a)

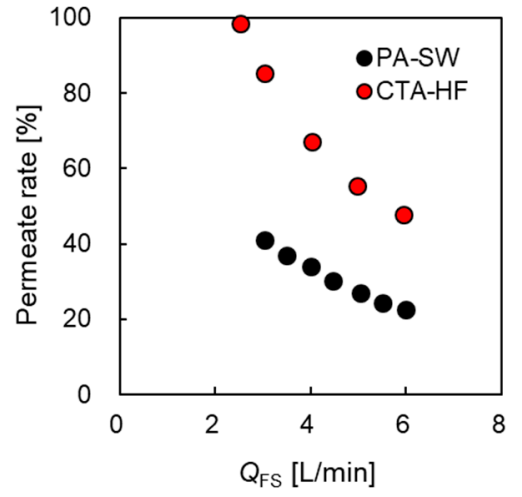

(b)

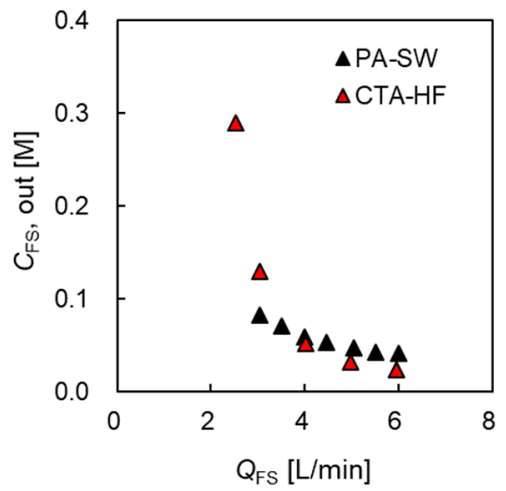

(c)

Figure 5. (a) Water flux, $J_{w}$, and (b) FS permeation rate, $\eta$, and (c) the concentration of the module outlet at FS side $\left(C_{\mathrm{FS} \text {,out }}\right)$, respectively, as a function of FS flow rate, $Q_{\mathrm{FS}}$. DS: $1.2 \mathrm{M} \mathrm{NaCl}$. FS: treated tap water. $Q_{\mathrm{DS}}: 10.0 \mathrm{~L} / \mathrm{min} . \Delta P: 1.6 \mathrm{MPa}$ for PA-SW module and 2.5 MPa for CTA-HF module.

Permeate Water Flux and Dilution Factor Versus DS Flow Rate

The effect of the DS flow rate $\left(Q_{D S}\right)$ on the PRO performance was investigated by measuring the PRO performance of the two modules at various $Q_{\mathrm{DS}}$ to evaluate the effect of dilutive external concentration polarization ( $\mathrm{dECP})$ at the DS side and the decrease in the salt concentration in the module inside the DS side. Figure 6 shows $J_{w}$, dilution factor $(\varphi)$, and the concentration of the module outlet at the DS side $\left(Q_{\mathrm{DS}, \text { out }}\right)$ as a function of $Q_{\mathrm{DS}}$, where DS and FS are $0.6 \mathrm{M} \mathrm{NaCl}$ and tap water, respectively. $Q_{\mathrm{FS}}$ was set as $5.0 \mathrm{~L} / \mathrm{min}$, and $\Delta P$ was $1.2 \mathrm{MPa}$, which is nearly equal to the osmotic pressure difference between DS and FS.

Figure 6 a shows that $J_{w}$ increased from 0.53 at $1.0 \mathrm{~L} / \mathrm{min}$ to $1.7 \mathrm{~L} / \mathrm{m}^{2} \mathrm{~h}$ at $10 \mathrm{~L} / \mathrm{min}$ of $Q_{\mathrm{DS}}$ for CTA-HF and from 5.3 at $4.0 \mathrm{~L} / \mathrm{min}$ to $6.5 \mathrm{~L} / \mathrm{m}^{2} \mathrm{~h}$ at $10 \mathrm{~L} / \mathrm{min}$ for PA-SW as $Q_{\mathrm{DS}}$ increased, even as it approached the maximum flow rate of the pump. As $\varphi$ approaches 1 , it indicates that $Q_{\mathrm{DS} \text {,out }}$ is equal to the DS flow rate at the inlet. In this case, $\varphi$ decreased from 1.58 at $1.0 \mathrm{~L} / \mathrm{min}$ to 1.18 at $10 \mathrm{~L} / \mathrm{min}(\mathrm{CTA}-\mathrm{HF})$ and from 1.33 at $4 \mathrm{~L} / \mathrm{min}$ to 1.17 at $10 \mathrm{~L} / \mathrm{min}$ (PA-SW), as shown in Figure $6 \mathrm{~b}$. In the case of CTA-HF, $\mathrm{C}_{\mathrm{DS} \text {,out }}$ increased from $0.38 \mathrm{M}$ at $1.0 \mathrm{~L} / \mathrm{min}$ to $0.51 \mathrm{M}$ at $10 \mathrm{~L} / \mathrm{min}, 63 \%$ and $85 \%$ of the DS inlet concentration, respectively. In the case of PA-SW, $C_{\mathrm{DS} \text {, out }}$ increased from $0.45 \mathrm{M}$ and $0.51 \mathrm{M}, 75 \%$ and $85 \%$ of the DS inlet concentration, respectively, as $Q_{\mathrm{DS}}$ increased, as shown in Figure 6c. This indicates that a $10 \mathrm{~L} / \mathrm{min}$ of DS flow rate is not sufficient for both modules to be negligible in the DS dilution effect by the permeate water flow from the FS side. 


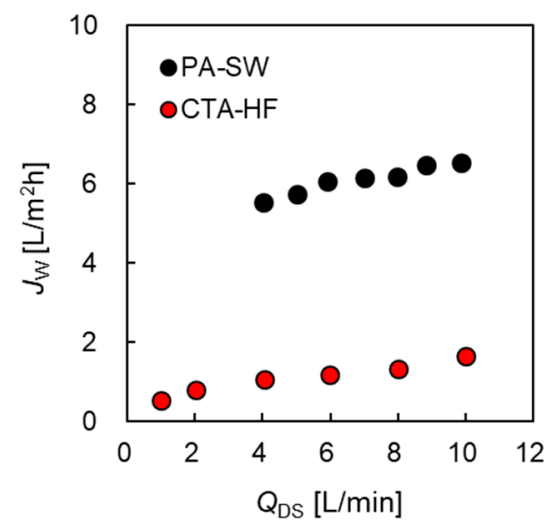

(a)

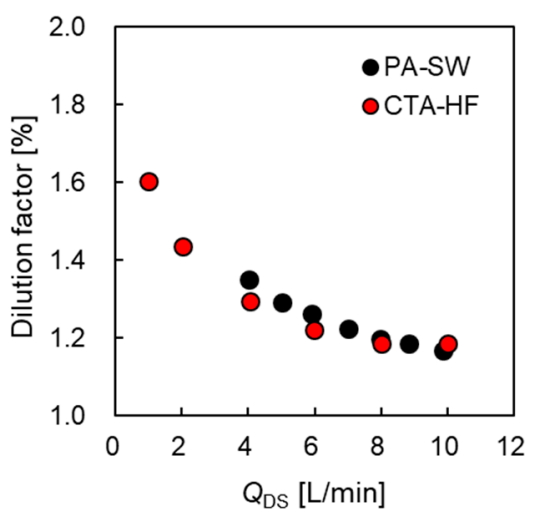

(b)

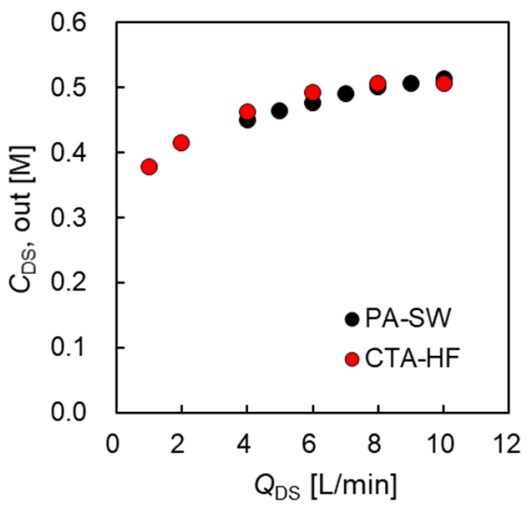

(c)

Figure 6. (a) Water flux, $J_{w}$, and (b) dilution factor, $\varphi$, and (c) the concentration of the module outlet at DS side $\left(C_{\mathrm{DS} \text {,out }}\right)$, respectively, as a function of DS flow rate, $Q_{\mathrm{DS}}$. DS: $0.6 \mathrm{M} \mathrm{NaCl}$. FS: treated tap water. $Q_{\mathrm{FS}}: 5.0 \mathrm{~L} / \mathrm{min} . \Delta P: 1.2 \mathrm{MPa}$.

When using 1.2 $\mathrm{M} \mathrm{NaCl}$ as DS, Figure 7 a shows that $J_{w}$ increased from 2.32 at $4.0 \mathrm{~L} / \mathrm{min}$ to $2.9 \mathrm{~L} / \mathrm{m}^{2} \mathrm{~h}$ at $10 \mathrm{~L} / \mathrm{min}$ of $Q_{\text {DS }}$ for CTA-HF. For PA-SW, $J_{w}$ increased from 5.1 at $4.0 \mathrm{~L} / \mathrm{min}$ to $5.6 \mathrm{~L} / \mathrm{m}^{2} \mathrm{~h}$ at $10 \mathrm{~L} / \mathrm{min}$ of $Q_{\mathrm{DS}}$. Similar to the case of FS flow rate change, $J_{w}$ of CTA-HF was higher compared to that in the case of $0.6 \mathrm{M}$, even though $\Delta P$ increased; however, that of PA-SW had a lower value. $\varphi$ decreased from 1.65 at $4.0 \mathrm{~L} / \mathrm{min}$ to 1.33 at $10 \mathrm{~L} / \mathrm{min}$ (CTA-HF) and from 1.32 at $4 \mathrm{~L} / \mathrm{min}$ to 1.14 at $10 \mathrm{~L} / \mathrm{min}$ (PA-SW), as shown in Figure $7 \mathrm{~b}$. $\mathrm{C}_{\mathrm{DS} \text {,out }}$ increased from $0.73 \mathrm{M}$ at $4.0 \mathrm{~L} / \mathrm{min}$ to $0.90 \mathrm{M}$ at $10 \mathrm{~L} / \mathrm{min}$ for CTA-HF, $61 \%$ and $75 \%$ of the DS inlet concentrations, respectively, and from $0.90 \mathrm{M}$ at $4.0 \mathrm{~L} / \mathrm{min}$ to $1.0 \mathrm{M}$ at $10 \mathrm{~L} / \mathrm{min}$ for PA-SW, 75\% and 83\% of the DS inlet concentration, respectively, as shown in Figure 7c. Even at the highest DS flow rate of the evaluation system (10 L/min), especially in the case of CTA-HF, $\varphi$ showed a high value (more than 1.3), and $C_{\mathrm{DS} \text {,out }}$ was much lower than the DS inlet concentration. This is because the permeate water flow of the module for CTA-HF was approximately two times higher than that of PA-SW; although, the water flux of the former was approximately half that of the latter at $10 \mathrm{~L} / \mathrm{min}$, indicating that the dilution effect to reduce the PRO performance cannot be negligible, especially for CTA-HF under the test conditions. 


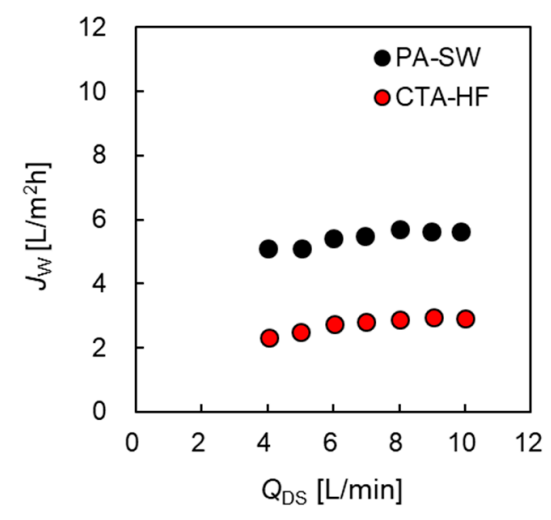

(a)

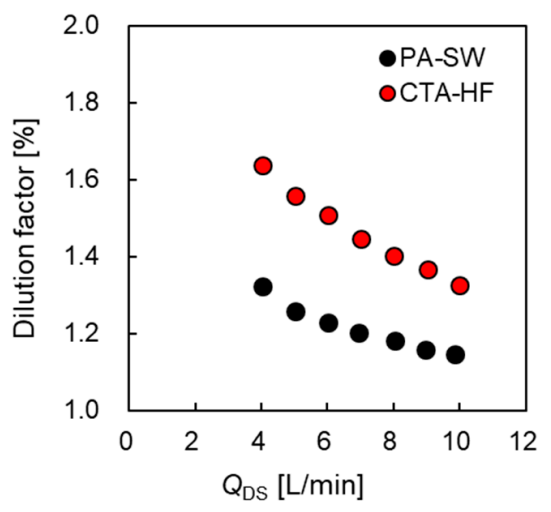

(b)

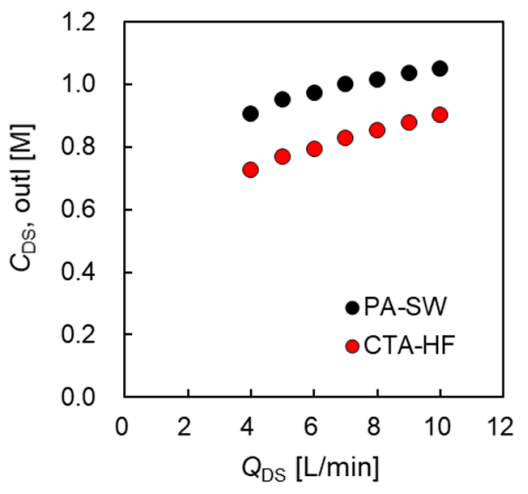

(c)

Figure 7. (a) Water flux, $J_{w}$, and (b) dilution factor, $\varphi$, and (c) the concentration of the module outlet at DS side $\left(C_{\mathrm{DS} \text {,out }}\right)$, respectively, as a function of DS flow rate, $Q_{\mathrm{DS}}$. DS: $1.2 \mathrm{M} \mathrm{NaCl}$. FS: treated tap water. $\mathrm{Q}_{\mathrm{FS}}: 5.0 \mathrm{~L} / \mathrm{min} . \triangle P: 1.6 \mathrm{MPa}$ for PA-SW module and $2.5 \mathrm{MPa}$ for CTA-HF module.

\subsubsection{PRO Performance of the Two Modules as a Function of Applied Pressure}

Figure 8a,b shows the relationship between $J_{w}$ and $\triangle P$ of CTA-HF and PA-SW, respectively, at various inlet DS concentrations $\left(C_{\mathrm{DS}}\right)$, where the flow rates of DS and FS were 10.0 and $5.0 \mathrm{~L} / \mathrm{min}$, respectively. As shown in Equation (1) and Figure 1, the measured water flux of both modules decreased with increasing $\Delta P$ because $\Delta P$ facilitates water movement from the DS to FS sides. The measured water flux increased with increasing $C_{\mathrm{DS}}$, owing to the increase in the driving force of water permeation and the osmotic pressure difference.

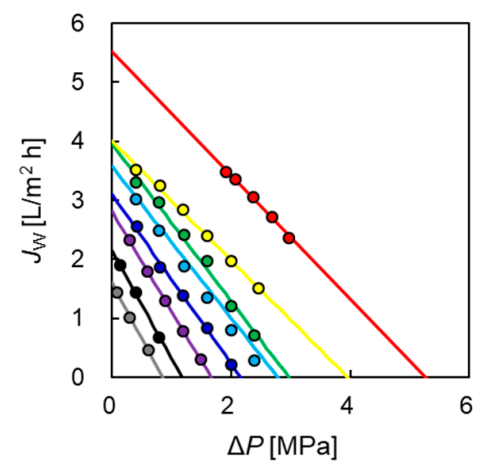

(a)

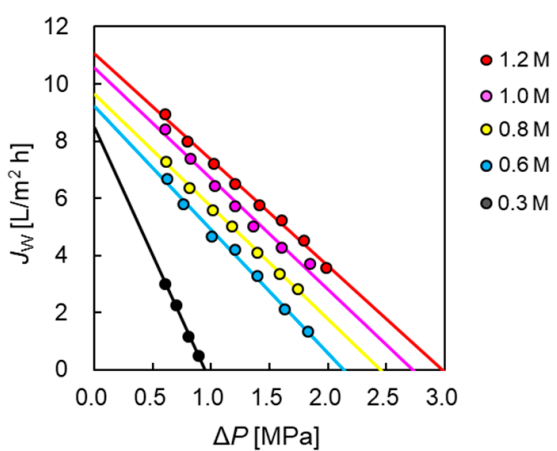

(b)

Figure 8. Water flux, $J_{w}$, as a function of applied hydraulic pressure difference, $\Delta P$, at $Q_{\mathrm{DS}}=10.0 \mathrm{~L} / \mathrm{min}$ and $Q_{\mathrm{FS}}=5.0 \mathrm{~L} / \mathrm{min}$ : (a) PA-SW and (b) CTA-HF membrane module. 
Although relationship between $J_{w}$ and $\Delta P$, given by Equation (1) indicates a linear relationship, in general, the actual $J_{w}$ in a PRO system decreases along the parabolic curve with increasing $\Delta P$ [29]. However, the obtained water flux of both modules decreased almost linearly with increasing $\Delta P$. This is primarily because the PRO tests in this study were performed at high DS and FS flow rates to minimize the effect of the DS dilution, dECP at the DS side by the permeate water flux, and the concentrated ICP inside the module by DS leakage, although these effects were not negligible, owing to the limitation of the pump performance, as shown in Figure 7. From the experimental results, the experimental water flux, $J_{w, \text { exp }}$, of the two modules under PRO conditions can be expressed in terms of a simple linear approximation as an empirical line [35]:

$$
J_{w, \exp }=A^{\mathrm{PRO}}\left(\Delta \pi_{\mathrm{eff}}-\Delta P\right)
$$

Here, the pseudo-water permeability in PRO mode $\left(A^{\mathrm{PRO}}\right)$ and effective osmotic pressure difference $\left(\Delta \pi_{\mathrm{eff}}\right)$ were obtained from the slope and intersection of the $x$-axis of the empirical line shown in Figure 8. The relationship between $\Delta \pi_{\text {eff }}$ and $C_{\mathrm{DS}}$ is shown in Figure 9. The broken line represents the theoretical osmotic pressure difference $(\Delta \pi)$ calculated by using the van't Hoff equation. This figure shows that $\Delta \pi_{\text {eff }}$ increased as $C_{\mathrm{DS}}$ increased, and $\Delta \pi_{\text {eff }}$ of the two modules was lower than $\Delta \pi$. Additionally, PA-SW exhibited a greater deviation between $\Delta \pi_{\text {eff }}$ and $\Delta \pi$, especially at high $C_{\mathrm{DS}}$. In contrast, CTA-HF shows a small deviation between the two values, and from the relationship between $\Delta \pi_{\text {eff }}$ and $C_{\text {DS }}$ shown in Figure $9, \Delta \pi_{\text {eff }}$ inside the module in the PRO test is estimated by using Equation (19), and $\alpha_{\text {mod }}$ is calculated as 0.88 :

$$
\Delta \pi_{\mathrm{eff}}=\alpha_{\mathrm{mod}} \Delta \pi
$$

The small deviation between $\Delta \pi$ and $\Delta \pi_{\text {eff }}$ for CTA-HF despite $Q_{D S \text {,out }}$ being $85 \%$ of the inlet concentration in the case of $0.6 \mathrm{M} \mathrm{NaCl}$ shown in Figure $6 \mathrm{c}$ indicates that the primary cause of the deviation will be the DS dilution, and the effect of the dilutive ECP on PRO performance will be negligible for the HF type module.

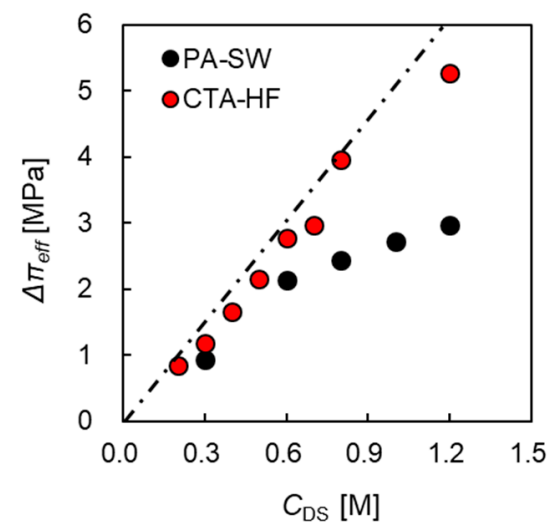

Figure 9. Effective osmotic pressure difference, $\Delta \pi_{\text {eff }}$, as a function of DS concentration, $C_{\mathrm{DS}}$. FS: treated tap water. $Q_{\mathrm{DS}}: 10.0 \mathrm{~L} / \mathrm{min}$. $Q_{\mathrm{FS}}: 5.0 \mathrm{~L} / \mathrm{min}$.

The possible reasons that the dilutive ECP ( $\mathrm{dECP}$ ) will be negligible are as follows: A hollow-fiber-type membrane element has an approximately 10-times-larger surface area (than SW type) in the case of an RO module [42]. This implies that the water flux per membrane area of an HF module is much lower than that of an SW module, even if the two modules have the same water flux per module. Hence, the effect of dECP on the DS side will be lower because of the small water flux per membrane area of the HF module. Additionally, the cross-winding arrangement of more than several thousands of hollow fibers in an HF module allows a uniform flow, which minimizes the concentration polarization in the shell side (the DS side in this study) of the module [42]. 
The other possible reasons for the deviations $\Delta \pi$ and $\Delta \pi_{\text {eff }}$ are that the smaller $B$ value of CTA-HF compared to PA-SW will give a lower concentrative ICP inside the support layer of the membrane.

Figure 10 shows the apparent water permeation coefficient $A^{\mathrm{PRO}}$ as a function of $C_{\mathrm{DS}}$. The $A^{\text {PRO }}$ of CTA-HF decreased gradually from $1.9 \times 10^{-6}$ at $0.2 \mathrm{M} \mathrm{NaCl}$ to $1.0 \times 10^{-6}$ $\left[\mathrm{L} / \mathrm{m}^{2} \mathrm{~h} \mathrm{~Pa}\right]$ at $1.2 \mathrm{M}$ of $C_{\mathrm{DS}}$, which is similar to the decrease of the CTA-HF reported in a previous study [43] named as M-HF in Table 2. $A^{\mathrm{PRO}}$ of PA-SW decreased drastically from 9.0 at $0.3 \mathrm{M}$ of $C_{\mathrm{DS}}$ to $3.7 \times 10^{-6}\left[\mathrm{~L} / \mathrm{m}^{2} \mathrm{~h} \mathrm{~Pa}\right.$ ] at $1.2 \mathrm{M}$ DS. As shown in Figures 9 and 10, the drastic decrease in $\Delta \pi_{\mathrm{eff}}$ and $A^{P R O}$ of PA-SW is due to the concentrated ICP inside the support layer of the PA membrane involving the DS leakage because the membrane has lower salt rejection than the CTA membrane, as shown in Figure 3b. Another factor may be the complex FS flow channel structure of the PRO SW module in a U-fashion [48]. It may be difficult for the channel structure to flush the DS leakage at a high $C_{\mathrm{DS}}$.

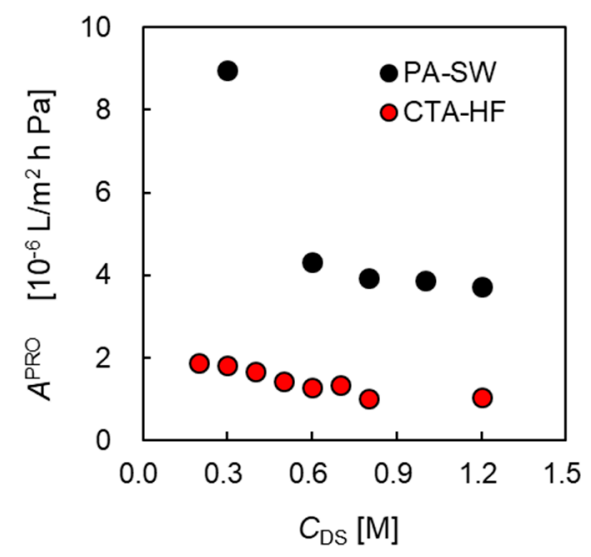

Figure 10. Apparent water permeability coefficient, $A^{\mathrm{PRO}}$, as a function of DS concentration, $C_{\mathrm{DS}}$. FS: treated tap water. $Q_{\mathrm{DS}}: 10.0 \mathrm{~L} / \mathrm{min}$. $Q_{\mathrm{FS}}: 5.0 \mathrm{~L} / \mathrm{min}$.

\subsubsection{Comparison of PRO Module Performance between CTA-HF and PA-SW}

The volumetric power density of the hollow-fiber-type module (CTA-HF) and spiralwound type of membrane module (PA-SW) were compared to investigate the feasible operating conditions for generating energy by using the PRO technique. In this section, a detailed comparison was performed to evaluate the volumetric power density as a function of the applied hydrostatic pressure difference, and the maximum gross power, maximum net power output, and pumping energy for feeding DS and FS as a function of the flow rates of the DS and FS.

\section{Volumetric Gross Power Density and Applied Pressure Difference}

Figure 11a,b shows the volumetric gross power density $\left(P D^{\mathrm{vol}}\right)$ of PA-SW and CTA-HF in relation to $\Delta P$, respectively. Here, each circle represents the experiments obtained under the operating conditions where $Q_{\mathrm{DS}}$ and $Q_{\mathrm{FS}}$ are 10 and $5 \mathrm{~L} / \mathrm{min}$, respectively, and each curve is the calculation obtained by substituting $A^{\mathrm{PRO}}$ and $\Delta \pi_{\text {eff }}$ into Equations (9) and (18). These figures indicate that the $P D^{\mathrm{vol}}$ of both modules increased with increasing $\Delta P$, and they reached a maximum value at approximately half of $\Delta \pi_{\text {eff }}$ at each $C_{\mathrm{DS}}$. The maximum volumetric gross power density $\left(P D_{\max }^{\text {gross }}\right)$ and the applied hydrostatic pressure difference at the point that indicates $P D_{\max }^{\text {gross }}$ increased when $C_{\mathrm{DS}}$ increased, as predicted by Equation (18). Compared to $P D_{\max }^{\text {gross }}$ of PA-SW and CTA-HF, in the case of $1.2 \mathrm{M} \mathrm{NaCl}$ (SWRO brine level) as DS, $P D_{\max }^{\text {gross }}$ of CTA-HF was $13.6 \mathrm{~kW} / \mathrm{m}^{3}$ at $2.6 \mathrm{MPa}$ of $\Delta P$, and that of PA-SW was $1.1 \mathrm{~kW} / \mathrm{m}^{3}$ at $1.5 \mathrm{MPa}$ of $\Delta P$. Hence, CTA-HF showed 12 times higher $P D_{\max }^{\text {gross }}$ than PA-SW. In the case of $0.6 \mathrm{M} \mathrm{NaCl}$ (seawater level) as DS, $P D_{\max }^{\text {gross }}$ of CTA-HF was $4.7 \mathrm{~kW} / \mathrm{m}^{3}(\Delta P=1.4 \mathrm{MPa})$, and that of PA-SW is $0.63 \mathrm{~kW} / \mathrm{m}^{3}(\triangle P=1.1 \mathrm{MPa})$, indicating 7.5 times higher $P D_{\max }^{\text {gross }}$ of CTA-HF. This is because of the difference in the packing density 
(the ratio of membrane area to module volume) between the two module configurations. The packing densities of CTA-HF and PA-SW were $6.75 \times 10^{3}$ and $4641 / \mathrm{m}$, respectively; thus, that of CTA-HF was 14 times higher than that of PA-SW. Therefore, the permeate water flux of CTA-HF is higher than that of PA-SW, even though the water flux per unit membrane area of the latter is approximately three times higher than that of the former, as shown in Figure 6a, and CTA-HF has only 30\% of the module volume compared to PA-SW. The total membrane area of PA-SW $\left(15.3 \mathrm{~m}^{2}\right)$ is approximately $40 \%$ that of a conventional RO SW module $\left(37 \mathrm{~m}^{2}\right)$. This is owing to the thicker tricot fabric spacer at the FS side and larger dead membrane area due to the presence of additional glue lines along the central line of the membranes to fabricate in a U-shaped fashion [48], compared to a conventional RO SW module.

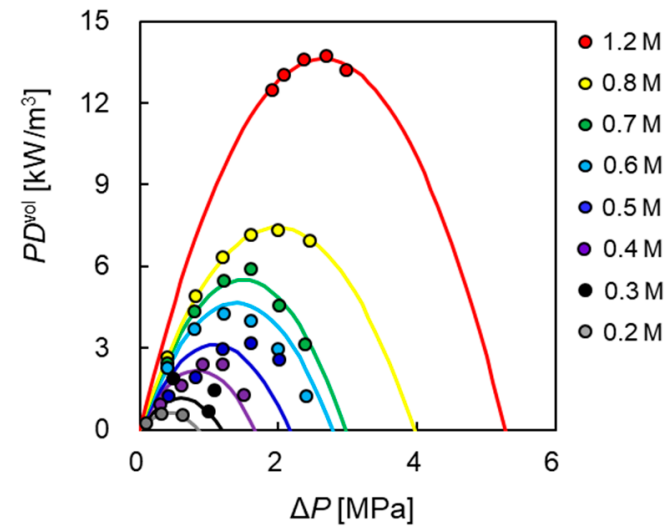

(a)

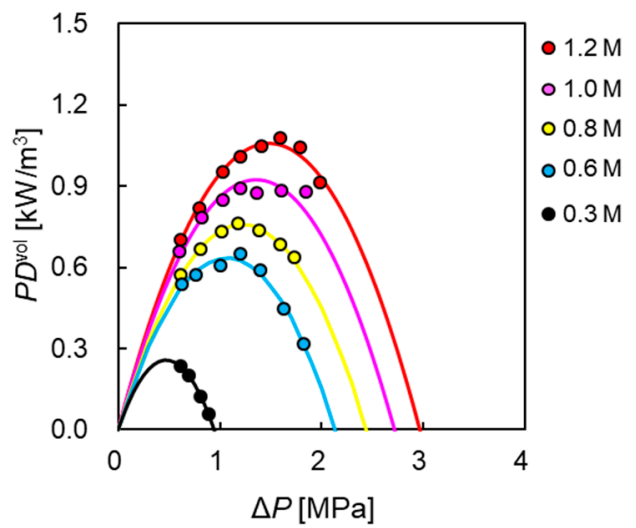

(b)

Figure 11. Volumetric gross power density, $P D^{\mathrm{vol}}$, as a function of applied hydraulic pressure difference, $\Delta P$, membrane module: (a) PA-SW and (b) CTA-HF with FS: treated tap water. $Q_{\mathrm{DS}}$ $10.0 \mathrm{~L} / \mathrm{min}$. $Q_{\mathrm{FS}}: 5.0 \mathrm{~L} / \mathrm{min}$.

To investigate the relationship between $P D_{\max }^{\text {gross }}$ and DS concentration in greater detail, Figure 12 shows the $P D_{\max }^{\text {gross }}$ of CTA-HF and PA-SW as a function of $Q_{D S}$. The $P D_{\max }^{\text {gross }}$ of CTA-HF increased in an approximate quadratic curve with increasing $C_{D S}$. In the theoretical Equations (1) and (9), the power output of PRO becomes a quadratic curve of $C_{\text {DS }}$ because the power output is the product of the water flux and the osmotic pressure difference, and these two factors depend linearly on $C_{D S}$. Conversely, the degree of the increase in $P D_{\max }^{\text {gross }}$ of PA-SW was smaller than that of CTA-HF, indicating that there is a large difference in $P D_{\max }^{\text {gross }}$ between the two modules, especially at high DS concentrations. The primary causes of this difference are the difference in $\Delta \pi_{\text {eff }}$ and $A^{P R O}$ at high DS concentrations and the packing density between the two modules. 


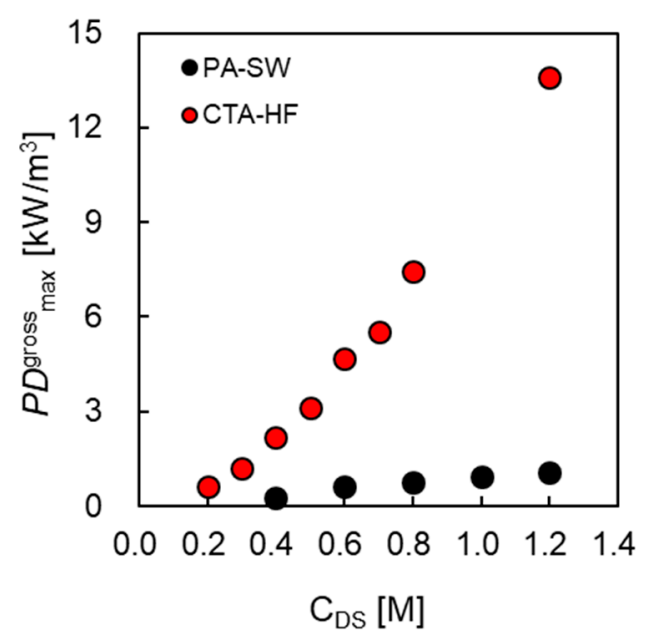

Figure 12. The maximum gross power output $\left(P D_{\max }^{\text {gross }}\right)$ of CTA-HF and PA-SW as a function of $C_{\mathrm{DS}}$. FS: treated tap water. $Q_{\mathrm{DS}} 10.0 \mathrm{~L} / \mathrm{min} . Q_{\mathrm{FS}}: 5.0 \mathrm{~L} / \mathrm{min}$.

Relationship between Net Power Output and Feed Flow Rates of DS and FS

The theoretical power output of the membrane module was calculated from the water flux and applied pressure difference. However, in an actual PRO plant, the efficiency of the pumps and PX used for PRO operation must be carefully considered. Hence, in this section, the gross power, net power per module, and pumping energy in the PA-SW and CTA-HF systems were compared, using $1.2 \mathrm{M} \mathrm{NaCl}$ as DS, at various flow rates of DS and FS. Here, tap water was used as FS, and $\Delta P$ for PA-SW and CTA-HF were 1.6 and $2.5 \mathrm{MPa}$, respectively. Figure $13 \mathrm{a}, \mathrm{b}$ shows the gross power $\left(P_{\text {gross }}\right)$, net power $\left(P_{\text {net }}\right)$, and pumping energy $(P E)$ per module for PA-SW and CTA-HF as a function of FS flow rate. Figure 13a shows that $P_{\text {gross }}$ of PA-SW increased from 28 to $35 \mathrm{~W}$ at $6 \mathrm{~L} / \mathrm{min}$, indicating a 1.25 -fold increase from 3 to $6 \mathrm{~L} / \mathrm{min} Q_{\mathrm{FS}}$, while $C E$ increased rapidly from 20 to $44 \mathrm{~W}$ (2.2-fold increase). The $P_{\text {net }}$ of the module decreased from $9.3 \mathrm{~W}$ and showed negative values at flow rates of more than $5 \mathrm{~L} / \mathrm{min}$. Hence, $P_{\text {net }}$ had a maximum value of $9.3 \mathrm{~W}$ at $3.0 \mathrm{~L} / \mathrm{min}$ of $Q_{\mathrm{FS}}$ under the test conditions. Meanwhile, as shown in Figure $13 \mathrm{~b}, P_{\text {gross }}$ of CTA-HF increased from 93 to $123 \mathrm{~W}$, a 1.3-fold increase with increasing $Q_{\mathrm{FS}}$ from 3 to $6 \mathrm{~L} / \mathrm{min}$. The $C E$ increased rapidly from 43 to $98 \mathrm{~W}$ (2.3-fold increase). $P_{\text {net }}$ increased from $54 \mathrm{~W}$ and reached a maximum value of $55 \mathrm{~W}$ at $3 \mathrm{~L} / \mathrm{min}$ of $Q_{\mathrm{FS}}$, and then decreased to $23 \mathrm{~W}$ at $6 \mathrm{~L} / \mathrm{min}$ of $Q_{\text {FS. }}$. The maximum net power of the CTA-HF is more than five times that of the PA-SW. The changes in $P_{\text {gross }}, P_{\text {net }}$, and $C E$ with DS flow rate are shown in Figure $13 \mathrm{c}, \mathrm{d}$. The $P_{\text {gross }}$ of PA-SW increased from $33 \mathrm{~W}$ at $4 \mathrm{~L} / \mathrm{min}$ to $36 \mathrm{~W}$ at $10 \mathrm{~L} / \mathrm{min}$, indicating a 1.09-fold increase with increasing $Q_{\mathrm{DS}}$, while $C E$ increased rapidly from 22 to $32 \mathrm{~W}$ (1.45-fold increase). The $P_{\text {net }}$ of the module decreased from the maximum value of $11 \mathrm{~W}$ at $4.0 \mathrm{~L} / \mathrm{min}$ and showed negative values at flow rates of more than $9 \mathrm{~L} / \mathrm{min}$. For CTA-HF, $P_{\text {gross }}$ increased from $102 \mathrm{~W}$ at $4 \mathrm{~L} / \mathrm{min}$ to $128 \mathrm{~W}$ at $10 \mathrm{~L} / \mathrm{min}$, indicating a 1.25-fold increase with increasing $Q_{\mathrm{DS}}$, while $C E$ increased rapidly from 43 to $63 \mathrm{~W}$ (1.46-fold increase). Thus, $P_{\text {net }}$ of the module increased from $58 \mathrm{~W}$ at $4 \mathrm{~L} / \mathrm{min}$ and reached a maximum of $72 \mathrm{~W}$ at $6 \mathrm{~L} / \mathrm{min}$ and almost a constant value of $71 \mathrm{~W}$. From these results, the dependence of $Q_{\mathrm{FS}}$ for both modules on $C E$ is higher than that of $Q_{\mathrm{DS}}$. The rapid increase in $C E$ with increasing $Q_{\mathrm{FS}}$ for PA-SW is caused by the complex flow channel in the dense tricot spacer with high pressure resistance at the FS side mentioned above. For CTA-HF, small-diameter hollow fibers are used in the module. The evaluation indicates that as the flow rates of DS and FS increased for both modules, $P_{\text {gross }}$ increased. However, the rapid increase in CE for PRO operation with increasing flow rates of DS and FS reduced $P_{\text {net. }}$. PA-SW demonstrates a maximum value of $P_{\text {net }}$ at lower DS and FS flow rates than the operating conditions of the PRO test in this study. For CTA-HF, the optimal value of $Q_{\mathrm{DS}}$ and $Q_{\mathrm{FS}}$ are 6.0 and $3.0 \mathrm{~L} / \mathrm{min}$, respectively, under the test conditions. The rapid increase in $C E$ with increasing $Q_{\mathrm{FS}}$ is the primary cause of the reduction in the net power of the 
PRO system, especially for CTA-HF. Hence, a flow channel structure with a low pressure drop is necessary to increase the PRO power output.

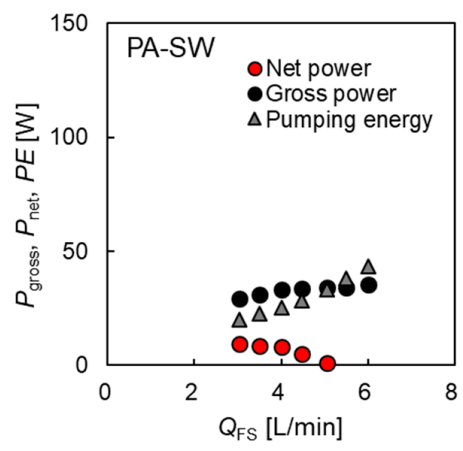

(a)

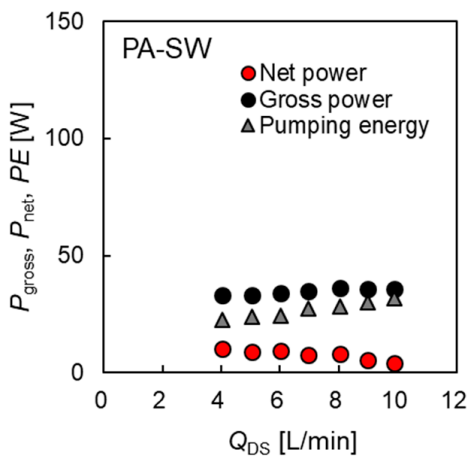

(c)

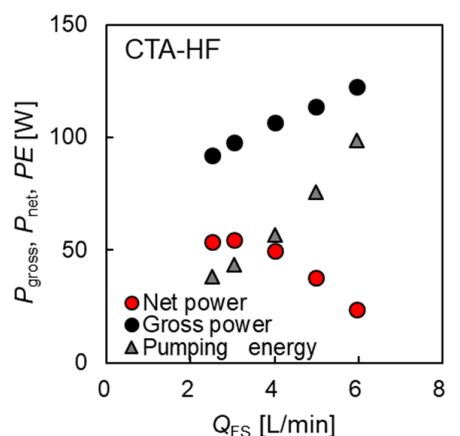

(b)

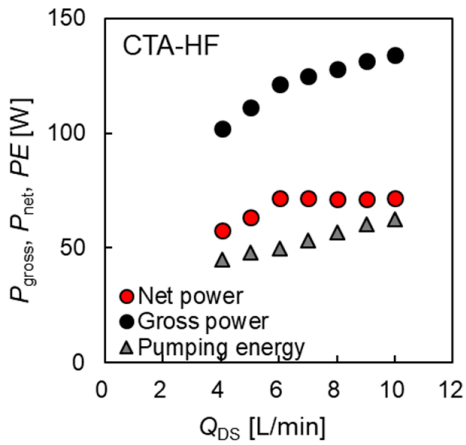

(d)

Figure 13. The gross power $\left(P_{\text {gross }}\right)$, net power $\left(P_{\text {net }}\right)$, and pumping energy $(P E)$ per a module as a function of flow rates of DS and FS, using PA-SW (a) and (c) and CTA-HF (b) and (d).

\subsubsection{Comparison of PRO Performance between Spiral-Wound and Hollow-Fiber Modules}

To compare the PRO module performances with different configurations, such as spiral wound (SW) and hollow fiber (HF), a comparison using volumetric-based power outputs, as well as membrane area-based power density, is needed to design a full-scale PRO plant. Table 2 shows the maximum power density per unit membrane area $\left(P D_{\text {max }}^{\text {area }}\right)$, maximum power density per unit volume $\left(P D_{\max }^{\mathrm{vol}}\right)$, test conditions, and module dimensions of the modules tested in this study and those in the literature. Kim et al. [37] evaluated the PRO performance of a prototype PRO SW module (M-SW) with an effective membrane area of $29 \mathrm{~m}^{2}$ of the TFC membrane. The dimensions of the module were $0.2 \mathrm{~m}$ (8 in.) in diameter and $1 \mathrm{~m}$ in length; hence, the module volume was estimated to be $31.4 \times 10^{-3} \mathrm{~m}^{3} . P D_{\text {max }}^{\text {area }}$ was reported as $1.0 \mathrm{~W} / \mathrm{m}^{2}$; thus, $P D_{\max }^{\mathrm{vol}}$ of the module was estimated as $0.92 \mathrm{~kW} / \mathrm{m}^{3}$, using $0.6 \mathrm{M} \mathrm{NaCl}$ as DS at $0.98 \mathrm{MPa}$ of $\Delta P$. In comparison with M-SW, PA-SW in this study demonstrated $40 \%$ higher $P D_{\max }^{\text {area }}\left(1.40 \mathrm{~W} / \mathrm{m}^{2}\right)$ and $74 \%$ of $P D_{\max }^{\text {vol }}\left(0.68 \mathrm{~kW} / \mathrm{m}^{3}\right)$. The smaller $P D_{\max }^{\mathrm{vol}}$ of PA-SW was due to approximately half of the packing density, owing to the smaller effective membrane area of PA-SW compared to M-SW.

Higa and Yasukawa et al. [35,43] evaluated the PRO performance of a CTA-HF module (M-HF). The effective membrane area and volume of the module were $72 \mathrm{~m}^{2}$ and $9.27 \times 10^{-3} \mathrm{~m}^{3}$, respectively. The packing density of M-HF was calculated as $77691 / \mathrm{m}$, the highest value in all the modules listed in Table 2. $P D_{\max }^{\text {area }}$ of the module increased from 0.14 at $0.5 \mathrm{M}$ to $0.44 \mathrm{~W} / \mathrm{m}^{2}$ at $0.9 \mathrm{M} \mathrm{NaCl}$ as DS, and $P D_{\max }^{\mathrm{vol}}$ changed from 1.09 at $0.5 \mathrm{M}$ to $3.39 \mathrm{~W} / \mathrm{m}^{2}$ at $0.9 \mathrm{M} \mathrm{NaCl}$. The effective membrane area of M-HF was $72 \mathrm{~m}^{2}$, which is 
higher than that of CTA-HF. This is because the outer diameter and number of HF using M-HF were $160 \mu \mathrm{m}$ and 214,000, respectively, while those of CTA-HF were $170 \mu \mathrm{m}$ and 187000. Hence, the packing density of the former is higher than that of CTA-HF. In a comparison of the power output between the two HF modules, CTA-HF shows approximately three times higher $P D_{\max }^{\text {area }}$ and $P D_{\max }^{\text {vol }}$ than $\mathrm{M}-\mathrm{HF}$. This is owing to higher $\mathrm{A}$ value $\left(0.65 \times 10^{-12}\left[\mathrm{~m} \mathrm{~s}^{-1} \mathrm{~Pa}^{-1}\right]\right)$ of the former than that of the latter $\left(0.25 \times 10^{-12}\left[\mathrm{~m} \mathrm{~s}^{-1} \mathrm{~Pa}^{-1}\right]\right)$ primarily because of the thinner membrane of CTA-HF $(40 \mu \mathrm{m})$ compared to that of M-HF $(50 \mu \mathrm{m})$ [35].

In a comparison of the power output between modules with different configurations, $P D_{\text {max }}^{\text {area }}$ of PA-SW was 2.03 -fold higher at $0.6 \mathrm{M} \mathrm{NaCl}$ and 1.16 -fold higher at $1.2 \mathrm{M} \mathrm{NaCl}$ than that of CTA-HF due to the higher water flux of PA-SW. Conversely, in a comparison using the volumetric-based power output, CTA-SW showed 6.87-fold higher $P D_{\max }^{\mathrm{vol}}$ at $0.6 \mathrm{M} \mathrm{NaCl}$ than PA-SW did. The difference in the $P D_{\max }^{\mathrm{vol}}$ between the two modules increased with increasing DS concentration, and CTA-HF had 12.0-fold higher $P D_{\max }^{\mathrm{vol}}$ at 1.2 $\mathrm{M} \mathrm{NaCl}$ as DS. The higher volumetric-based power density of CTA-HF is due to its higher packing density than that of PA-SW. Moreover, at high DS concentrations, the lower $B$ value of the CTA-HF reduces concentrative ICP due to DS leakage, and the lower water permeate per unit membrane area of HF membranes reduces the effect of dECP at the DS side on the PRO performance. To achieve a high volumetric-based power output for a spiral-wound membrane module, an increase in the packing density to optimize the FS flow channel structure is required. In addition, a low $B$ value to reduce DS leakage and high DS flow rates to decrease dECP are needed to improve the PRO performance of an SW module at high DS concentrations.

In this study, we compared the PRO performance between CTA-HF and PA-SW, using $\mathrm{NaCl}$ solutions of various concentrations as model DS. In a real PRO application, DS and FS will contain foulant substances, and there will be a difference in the effect of the foulants on the PRO performance between the two module configurations. For example, the more complex channel structure of the U fashion at the FS side of PA-SW will have a greater impact on the long-term stability than CTA-HF. Additionally, DS and FS contain not only monovalent ions such as $\mathrm{Na}^{+}$and $\mathrm{Cl}^{-}$ions but also bivalent ions such as $\mathrm{Mg}^{2+}, \mathrm{Ca}^{2+}$, and $\mathrm{SO}_{4}{ }^{2-}$ ions. The difference in the reverse flux between the monovalent ions and the bivalent ions will affect the FS up-concentration on the PRO performance and also the difference in the membrane fouling by forming aggregates between the bivalent ions and foulants in FS, such as humic acid [49].

Table 2. Comparison between the dimensions and power densities of PRO modules from the literature and the current study.

\begin{tabular}{|c|c|c|c|c|c|c|c|c|c|}
\hline Module & Type & $\begin{array}{c}S_{m} \\
\left(\mathrm{~m}^{2}\right)\end{array}$ & $\begin{array}{c}V_{m} \\
\left(m^{3}\right) \times 10^{-3}\end{array}$ & $\begin{array}{c}\beta \\
(1 / \mathrm{m})\end{array}$ & $\begin{array}{l}\mathrm{DS}(\mathrm{M} \\
\mathrm{NaCl})\end{array}$ & $\begin{array}{l}\Delta P \text { at } P D_{\max } \\
(\mathrm{M} \mathrm{Pa})\end{array}$ & $\begin{array}{c}P D_{\max }^{\text {area }} \\
\left(\mathrm{W} / \mathrm{m}^{2}\right)\end{array}$ & $\underset{\left(\mathrm{kW} / \mathrm{m}^{3}\right)}{P D_{\max }^{\mathrm{vol}}}$ & Reference \\
\hline M-SW & SW & 29 & 31.4 & 923 & 0.6 & 0.98 & 1.0 & 0.92 & [37] \\
\hline \multirow{4}{*}{ M-HF } & \multirow{4}{*}{$\mathrm{HF}$} & \multirow{4}{*}{72} & \multirow{4}{*}{9.27} & \multirow{4}{*}{7769} & 0.5 & 0.94 & 0.14 & 1.09 & [35] \\
\hline & & & & & 0.6 & 1.1 & 0.17 & 1.32 & [43] \\
\hline & & & & & 0.8 & 1.7 & 0.35 & 2.74 & [43] \\
\hline & & & & & 0.9 & 1.8 & 0.44 & 3.39 & [43] \\
\hline \multirow{3}{*}{ PA-SW } & \multirow{3}{*}{ SW } & \multirow{3}{*}{15.3} & \multirow{3}{*}{31.4} & \multirow{3}{*}{487} & 0.6 & 1.2 & 1.40 & 0.68 & \multirow{3}{*}{ This study } \\
\hline & & & & & 0.8 & 1.2 & 1.64 & 0.80 & \\
\hline & & & & & 1.2 & 1.6 & 2.33 & 1.13 & \\
\hline \multirow{4}{*}{ CTA-HF } & \multirow{4}{*}{$\mathrm{HF}$} & \multirow{4}{*}{67} & \multirow{4}{*}{9.92} & \multirow{4}{*}{6770} & 0.5 & 1.6 & 0.47 & 3.21 & \multirow{4}{*}{ This study } \\
\hline & & & & & 0.6 & 1.2 & 0.69 & 4.67 & \\
\hline & & & & & 0.8 & 2.0 & 1.09 & 7.36 & \\
\hline & & & & & 1.2 & 3.0 & 2.01 & 13.61 & \\
\hline
\end{tabular}




\section{Conclusions}

In this study, permeate water flux in PRO mode, using two pilot-scale PRO membrane modules with different configurations, a five-inch cellulose triacetate hollow-fiber membrane module (CTA-HF) and eight-inch polyamide spiral-wound membrane modules (PA-SW), was measured by changing the DS concentration, the applied hydrostatic pressure difference, and the flow rates of the DS and FS, to obtain the optimum operating conditions in the PRO configuration. The following conclusions were drawn from this study:

The water permeability of PA-SW was approximately seven times higher than that of CTA-HF. In comparison, the salt permeability of PA-SW was approximately 13 times higher than that of CTA-HF, indicating that the CTA-HF membrane will have a lower DS leakage than PA-SW.

An FS flow rate of more than $5 \mathrm{~L} / \mathrm{min}$ is sufficient for the two modules to mitigate the effect of FS up-concentration on PRO performance. However, $10 \mathrm{~L} / \mathrm{min}$ of DS flow rate cannot make the dilution effect negligible, especially at high DS concentrations $\left(C_{\mathrm{DS}}\right)$.

PA-SW showed a significant deviation between the theoretical and effective osmotic pressure differences obtained from the water flux vs. the applied hydrostatic pressure curves in the PRO test, especially at high CDSs. In contrast, the CTA-HF showed a small deviation between the two values.

The FS flow rate's $\left(Q_{\mathrm{FS}}\right)$ dependence for both modules on the pumping energy for PRO operation is higher than that for DS flow rate. The rapid increase in the pumping energy with increasing $Q_{\mathrm{FS}}$ is due to the complex U-shaped flow channel in the dense tricot spacer at the FS side for PA-SW and the small diameter of hollow fibers used in CTA-HF.

The maximum power density per unit membrane area $\left(P D_{\max }^{\mathrm{area}}\right)$ of PA-SW was 2.03 -fold higher at $0.6 \mathrm{M} \mathrm{NaCl}$ and 1.16-fold higher at $1.2 \mathrm{M} \mathrm{NaCl}$ than that of CTA-HF, owing to the higher water flux of PA-SW. Conversely, in a comparison using the maximum power density per unit volume $\left(P D_{\max }^{\mathrm{vol}}\right), \mathrm{CTA}-\mathrm{SW}$ showed a 6.87 -fold higher $P D_{\max }^{\mathrm{vol}}$ at $0.6 \mathrm{M}$. The difference in the $P D_{\max }^{\mathrm{vol}}$ between the two modules increased with the increasing DS concentration, and CTA-HF had 12.0-fold higher $P D_{\max }^{\mathrm{vol}}$ at $1.2 \mathrm{M} \mathrm{NaCl}$ as DS than PA-SW did. This is owing to the high packing density of the CTA-HF.

Author Contributions: Conceptualization, M.H.; methodology, M.H.; investigation, Y.K. and M.H.; data curation, Y.I. and M.S.; writing—original draft preparation, Y.K.; writing-review and editing, N.J. and M.H.; supervision, M.H.; project administration, M.H. All authors have read and agreed to the published version of the manuscript.

Funding: This research was funded by the Japan Society for the Promotion of Science (JSPS) through the "Funding Program for World-Leading Innovative R\&D on Science and Technology (FIRST Program)", initiated by the Council for Science and Technology Policy (CSTP). The authors appreciate the support from NEDO for the Mega-Ton Water System project.

Conflicts of Interest: The authors declare no conflict of interest.

\section{References}

1. IEA. CO2 Emission from Fuel Combustion-Highlights; IEA: Paris, France, 2014.

2. Kruyt, B.; Van Vuuren, D.P.; De Vries, H.G.M.; Geroenenberg, H. Indicators for energy security. Energy Policy $2009,2166-2181$. [CrossRef]

3. Ahiduzzaman, M.D.; Islam, A.K.M.S. Greenhouse gas emission and renewable energy sources for sustainable development in Bangladesh. Renew. Sust. Energ. Rev. 2011, 15, 4659-4666. [CrossRef]

4. Saito, K.; Irie, M.; Zaitsu, S.; Sakai, H.; Hayashi, H.; Tanioka, A. Power generation withsalinity gradient by pressure retarded osmosis using concentrated brine from SWROsystem and treated sewage as pure water. Desalin. Water Treat. 2012, 41, 114-121. [CrossRef]

5. $\quad$ Post, J.W.; Veerman, J.; Hamelers, H.-V.M.; Euverink, G.-J.W.; Metz, S.J.; Nymeijerc, K.; Buisman, C.J.N. Salinity-gradient power: Evaluation of pressure- retared osmosis and reverse electrodialysis. J. Membr. Sci. 2007, 288, 218-230. [CrossRef]

6. Avci, A.H.; Messana, D.A.; Santoro, S.; Tufa, R.A.; Curcio, E.; Profio, G.D.; Fontananova, E. Energy harvesting from brines by reverse elecrodialylsis using Nafion membranes. Membranes 2020, 10, 168. [CrossRef] [PubMed]

7. Tufa, R.A.; Curcio, E.; Brauns, E.; Van Baak, W.; Fontananova, E.; Di Profio, G. Membrane Distillation and Reverse Electrodialysis for Near-Zero Liquid Discharge and low energy seawater desalination. J. Memb. Sci. 2015, 496, 325-333. [CrossRef] 
8. Tufa, R.A.; Noviello, Y.; Di Profio, G.; Macedonio, F.; Ali, A.; Drioli, E.; Fontananova, E.; Bouzek, K.; Curcio, E. Integrated membrane distillation-reverse electrodialysis system for energy-ecient seawater desalination. Appl. Energy 2019, $253,113551$. [CrossRef]

9. Mei, Y.; Tang, C.Y. Resent developments and future perspectives of reverse electrodialysis technology: A review. Desalination 2018, 425, 156-174. [CrossRef]

10. Long, R.; Li, B.; Liu, Z.; Liu, W. Hybrid membrane distillation-reverse electrodialysis electricity generation system to harvest low-grade thermal energy. J. Memb. Sci. 2017, 525, 107-115. [CrossRef]

11. Helfer, F.; Lemckert, C.; Anissimov, Y.G. Osmotic power with pressure retarded osmosis: Theory, performance and trends-A review. J. Membr. Sci. 2014, 453, 337-358. [CrossRef]

12. Kim, J.; Jeong, K.; Park, M.J.; Shon, H.K.; Kim, J.H. Recent advances in osmotic energy generation via pressure-retarded osmosis (PRO): A review. Energies 2015, 8, 11821-11845. [CrossRef]

13. Linares, R.V.; Li, Z.; Sarp, S.; Bucs, S.S.; Amy, G.; Vrouwenvelder, J.S. Forward osmosis niches in seawater desalination and wastewater reuse. Water Res. 2014, 66, 122-139. [CrossRef] [PubMed]

14. Tedesco, M.; Scalici, C.; Vaccari, D.; Cipollina, A.; Tamburini, A.; Micale, G. Performance of the first reverse electrodialysis pilot plant for power production from saline waters and concentrated brines. J. Membr. Sci. 2016, 500, 33-45. [CrossRef]

15. Tedesco, M.; Cipollina, A.; Tamburini, A.; Micale, G. Towards $1 \mathrm{~kW}$ power production in a reverse electrodialysis pilot plant with saline waters and concentrated brines. J. Membr. Sci. 2017, 522, 226-236. [CrossRef]

16. Nam, J.-Y.; Hwang, K.-S.; Kim, H.-C.; Jeong, H.; Kim, H.; Jwa, E.; Yang, S.C.; Choi, J.; Kim, C.-S.; Han, J.-H.; et al. Assessing the behavior of the feed-water constituents of a pilot-scale 1000-cell-pair reverse electrodialysis with seawater and municipal wastewater effluent. Water Res. 2019, 148, 261-271. [CrossRef]

17. Mehdizadeh, S.; Kakihana, Y.; Abo, T.; Yuan, Q.; Higa, M. Power generation performance of a pilot-scale reverese elctrodialysis using monovalent selective ion-exchange membranes. Membranes 2021, 11, 27. [CrossRef]

18. Yasukawa, M.; Suzuki, T.; Higa, M. Salinity Gradient Processes: Thermodynamics, Application, and Future Prospects (Chapter 1). In Membrane-Based Salinity Gradient Processes for Water Treatment and Power Generation, 1st ed.; Elsevier: Amsterdam, The Netherlands, 2018; pp. 3-56.

19. Yip, N.Y.; Elimelech, M. Thermodynamic and energy efficiency analysis of power generation from natural salinity gradients by pressure retarded osmosi. Environ. Sci. Technol. 2012, 46, 5230-5239. [CrossRef] [PubMed]

20. Kim, Y.C.; Elimelech, M. Adverse impact of feed channel spacers on the performance of pressure retarded osmosis. Environ. Sci. Technol. 2012, 46, 4673-4681. [CrossRef]

21. She, Q.; Jin, X.; Tang, C.Y. Osmotic power production from salinity gradient resource by pressure retarded osmosis: Effects of operating conditions and reverse solute diffusion. J. Membr. Sci. 2012, 401-402, 262-273. [CrossRef]

22. Hoover, L.A.; Schiffman, J.D.; Elimelech, M. Nanofibers in thin-film composite membrane support layers: Enabling expanded application of forward and pressure retarded osmosis. Desalination 2013, 308, 73-81. [CrossRef]

23. Han, G.; Zhang, S.; Li, X.; Chung, T.-S. High performance thin film composite pressure retarded osmosis (PRO) membranes for renewable salinity-gradient energy generation. J. Membr. Sci. 2013, 440, 108-121. [CrossRef]

24. Zhang, S.; Fu, F.; Chung, T.-S. Substrate modifications and alcohol treatment on thin film composite membranes for osmotic power. Chem. Eng. Sci. 2013, 87, 40-50. [CrossRef]

25. She, Q.; Hou, D.; Liu, J.; Tan, K.H.; Tang, C.Y. Effect of feed spacer induced membrane deformation on the performance of pressure retarded osmosis (PRO): Implications for PRO process operation. J. Membr. Sci. 2013, 445, 170-182. [CrossRef]

26. Patel, R.; Chi, W.S.; Ahn, S.H.; Park, C.H.; Lee, H.-K.; Kim, J.H. Synthesis of poly(vinyl chloride)-g-poly(3-sulfopropyl methacrylate) graft copolymers and their use in pressure retarded osmosis (PRO) membranes. Chem. Eng. J. 2014, 247, 1-8. [CrossRef]

27. Han, G.; Wang, P.; Chung, T.S. Highly robust thin-film composite pressure retarded osmosis (PRO) hollow fiber membranes with high power densities for renewable salinity-gradient energy generation. Environ. Sci. Technol. 2013, 47, 8070-8077. [CrossRef]

28. Loeb, S.; Van Hessen, F.; Shahaf, D. Production of energy from concentrated brines by pressure-retarded osmosis: II. Experimental results and projected energy costs. J. Membr. Sci. 1976, 1, 249-269. [CrossRef]

29. Chou, S.; Wang, R.; Shi, L.; She, Q.; Tang, C.; Fane, A.G. Thin-film composite hollow fiber membranes for pressure retarded osmosis (PRO) process with high power density. J. Membr. Sci. 2012, 389, 25-33. [CrossRef]

30. Zhang, S.; Chung, T.-S. Minimizing the instant and accumulative effects of salt permeability to sustain ultrahigh osmotic power density. Environ. Sci. Technol. 2013, 47, 10085-10092. [CrossRef] [PubMed]

31. Fu, F.-J.; Sun, S.-P.; Zhang, S.; Chung, T.-S. Pressure retarded osmosis dual-layer hollow fiber membranes developed by co-casting method and ammonium persulfate (APS) treatment. J. Membr. Sci. 2014, 469, 488-498. [CrossRef]

32. Zhang, S.; Sukitpaneenit, P.; Chung, T.-S. Design of robust hollow fiber membranes with high power density for osmotic energy production. Chem. Eng. J. 2014, 241, 457-465. [CrossRef]

33. Wan, C.F.; Chung, T.-S. Osmotic power generation by pressure retarded osmosis using seawater brine as the draw solution and wastewater retentate as the feed. J. Membr. Sci. 2015, 479, 148-158. [CrossRef]

34. Straub, A.P.; Yip, N.Y.; Elimelech, M. Raising the bar: Increased hydraulic pressure allows unprecedented high power densities in pressure-retarded osmosis. Environ. Sci. Technol. Lett. 2014, 1, 55-59. [CrossRef] 
35. Higa, M.; Shigefuji, D.; Shibuya, M.; Izumikawa, S.; Ikebe, Y.; Yasukawa, M.; Endo, N.; Tanioka, A. Experimental study of a hollow fiber membrane module in pressure-retarded osmosis: Module performance comparison with volumetric-based power outputs. Desalination 2017, 420, 45-53. [CrossRef]

36. Xu, Y.; Peng, X.; Tang, C.Y.; Fu, Q.S.; Nie, S. Effect of draw solution concentration and operating conditions on forward osmosis and pressure retarded osmosis performance in a spiral wound module. J. Membr. Sci. 2010, 348, 298-309. [CrossRef]

37. Kim, Y.C.; Kim, Y.; Oh, D.; Lee, K.H. Experimental investigation of a spiral-wound pressure-retarded osmosis membrane module for osmotic power generation. Environ. Sci. Technol. 2013, 47, 2966-2973. [CrossRef]

38. Sakai, H.; Ueyama, T.; Irie, M.; Matsuyama, K.; Tanioka, A.; Saito, K.; Kumano, A. Energy recovery by PRO in sea water desalination plant. Desalination 2016, 389, 52-57. [CrossRef]

39. Kurihara, M.; Hanakawa, M. Mega-ton Water System: Japanese national research and development project on seawater desalination and wastewater reclamation. Desalination 2013, 308, 131-137. [CrossRef]

40. Kurihara, M.; Sakai, H.; Tanioka, A.; Tomioka, H. Role of pressure-retarded osmosis (PRO) in the mega-ton water project. Desalin. Water Treat. 2016, 57, 26518-26528. [CrossRef]

41. Hayashi, H.; Okumura, T. Macro and nano behavior of salt water in pressure retarded osmosis membrane module. Desalination 2016, 389, 155-161. [CrossRef]

42. Kumano, A.; Marui, K.; Terashima, Y. Hollow fiber type PRO module and its characteristics. Desalination 2016, 389, 149-154. [CrossRef]

43. Yasukawa, M.; Shigefuji, S.; Shibuya, M.; Ikebe, Y.; Horie, R.; Higa, M. Effect of DS concentration on the PRO performance using a 5-inch scale cellulose triacetate-based hollow fiber membrane module. Membranes 2018, 8, 22. [CrossRef]

44. Tanaka, Y.; Yasukawa, M.; Goda, S.; Sakurai, H.; Shibuya, M.; Takahashi, T.; Kishimoto, M.; Higa, M.; Matsuyama, H. Experimental and simulation studies of two types of 5-inch scale hollow fiber membrane modules for pressure-retarded osmosis. Desalination 2018, 447, 133-146. [CrossRef]

45. Kishimoto, M.; Tanaka, Y.; Yasukawa, M.; Goda, S.; Higa, M.; Matsuyama, H. Optimization of pressure-retarded osmosis with hollow-fiber membrane modules by numerical simulation. Ind. Eng. Chem. Res. 2019, 58, 6687-6695. [CrossRef]

46. Matsuyama, K.; Makabe, R.; Ueyama, T.; Sakai, H.; Saito, K.; Okumura, T.; Hayashi, H.; Tanioka, A. Power generation system based on pressure retarded osmosis with a commercially-available hollow fiber PRO membrane module using seawater and freshwater. Desalination 2021, 499, 114805. [CrossRef]

47. Achilli, A.; Cath, T.Y.; Childress, A.E. Power generation with pressure retarded osmosis: An experimental and theoretical investigation. J. Membr. Sci. 2009, 343, 42-52. [CrossRef]

48. Binger, Z.M.; Achilli, A. Forward osmosis and puressure retarded osmosis process modeling for integration with seawaer reverse osmosis desalination. Desalination 2020, 491, 114583. [CrossRef]

49. Touati, K.; Tadeo, F.; Kim, J.H.; Silva, O.A.A.; Chae, S.H. (Eds.) Oscar Andres Alvarez Silva, Pressure Retarded Osmosis: Renewable Energy Generation and Recovery; Academic Press: Cambridge, MA, USA, 2017. 